\title{
Patterns of Glutamate, Glycine, and GABA Immunolabeling in Four Synaptic Terminal Classes in the Lateral Superior Olive of the Guinea Pig
}

\author{
ROBERT H. HELFERT, JOSÉ M. JUIZ, SANFORD C. BLEDSOE, JR., JOANN M. \\ BONNEAU, ROBERT J. WENTHOLD, AND RICHARD A. ALTSCHULER \\ Kresge Hearing Research Institute, the University of Michigan, Ann Arbor, Michigan 48109 \\ (R.H.H., J.M.J., S.C.B., J.M.B., R.A.A.) and Laboratory of Molecular Otology, NIDCD, NIH, \\ Bethesda, Maryland 20205 (R.J.W.)
}

\begin{abstract}
The goal of this study was to correlate synaptic ultrastructure with transmitter specificity and function in the lateral superior olive (LSO), a nucleus that is thought to play a major role in sound localization. This was accomplished by means of postembedding immunogold immunocytochemistry. Four classes of synaptic terminals were identified in the LSO. They were distinguishable from one another both morphologically and on the basis of their different patterns of immunolabeling for glutamate, glycine, and $\gamma$-aminobutyric acid (GABA). The highest level of glutamate immunoreactivity was found in terminals that contained round vesicles $(R)$ and formed synaptic contacts with asymmetric synaptic junctions. Round-vesicle terminals predominated on small caliber dendrites by a ratio of at least $2: 1$ over the other classes combined. The thinnest dendrites were typically contacted by $\mathrm{R}$ terminals only. The ratio of $R$ terminals to the other types decreased as the caliber of the dendritic profiles they apposed increased so that on the soma, $R$ terminals were outnumbered by at least $2: 1$ by the other types. Terminals containing flattened vesicles $(F)$ exhibited intense immunoreactivity for both glycine and glutamate, although the glutamate immunolabeling was not as high as that in the $\mathrm{R}$ terminals. Flattened-vesicle terminals formed symmetric synaptic contacts with their targets and their distribution was the reverse of that described for $\mathrm{R}$ terminals; i.e., they were most abundant on LSO perikarya and fewest on small caliber dendrites. Two terminal types, both containing pleomorphic vesicles and forming symmetric synaptic junctions, were found in far fewer numbers. One group contained large pleomorphic vesicles (LP) and was immunoreactive for both glycine and GABA. The other group contained small pleomorphic vesicles (SP) along with a few dense-core vesicles and labeled for GABA only. The LP terminals were preferentially distributed on somata and large-caliber dendrites, while the SP terminals most often contacted smaller dendrites. Previous work suggests that a large percentage of the $R$ terminals arise from spherical cells in the ipsilateral cochlear nucleus and are excitatory in action. This pathway may use glutamate as a transmitter. Many of the $\mathrm{F}$ terminals are thought to originate from the ipsilateral medial nucleus of the trapezoid body and appear to be the inhibitory (glycinergic) terminals from a pathway that originates from the contralateral ear. The origins and functions of LP and SP terminals are unknown, but a few possibilities are discussed along with the significance of cocontainment of neuroactive substances in specific terminal types. 1992 Wiley-Liss, Inc.
\end{abstract}

Key words: amino acid neurotransmitters, colocalization of neurotransmitters, synaptic organization, auditory system, superior olivary complex, immunocytochemistry 
With the advent of postembedding immunocytochemical techniques, has come the opportunity to reassess in finer detail the correlation between structure and transmitter specificity of synapses in the central nervous system. At the ultrastructural level, the postembedding immunogold procedure permits quantitation of immunoreactive labeling so that semiquantitative and statistical comparisons can be made between different terminal types (e.g., Somogyi et al., '86; Montero and Wenthold, '89; Maxwell et al., '90). The ability to quantify immunolabeling is particularly important when attempting to elucidate a transmitter role for putative excitatory amino acids such as glutamate or aspartate, because their high metabolic levels tend to obscure their transmitter pools. When combined with knowledge of the sources of individual terminals, synaptic relations can be resolved to the level of simple networks, circuits or individual neurons. The benefits to be derived from this capability are clear: a better understanding of the synaptic organization as it pertains to circuit function and, ultimately, a better comprehension of the operation of whole neural systems.

Because of its uncomplicated cytoarchitecture and synaptic organization, the lateral superior olive (LSO) is an excellent system in which to evaluate and compare the cytochemical substrates of function among different anatomically defined synaptic terminals contained in a single nucleus. Behavioral studies suggest that the LSO, along with the neighboring medial superior olive (MSO), functions to determine the azimuth of sounds (Masterton et al., '79; Jenkins and Masterton, '82). The connectional, neurochemical, and electrophysiological data correlate well with this functional assignment. Most LSO neurons are sensitive to interaural intensity differences in that they are excited by ipsilateral sounds and suppressed by the simultaneous presentation of contralateral sounds (Tsuchitani and Boudreau, '66; Goldberg and Brown, '68; Guinan et al., '72a,b; Tsuchitani, '77; Brownell et al., '79; Caird and Klinke, '83; Moore and Caspary, '83; Finlayson and Caspary, '89). In addition, most LSO units are sensitive to interaural time differences, with maximal excitatory responses to ipsilateral time leads (Caird and Klinke, '83).

Recent studies have indicated that the excitation and inhibition of LSO neurons is mediated by synapses using amino acid transmitters (Moore and Caspary, '83; Schwartz, '85; Wenthold et al., '85; Sanes et al., '87; Glendenning and Baker, '88; Godfrey et al., '88; Helfert et al., '89a; Caspary and Faingold, '89; Finlayson and Caspary, '89; Wu and Kelly, '91), and preliminary work has suggested that at least four morphologically distinct classes of synaptic terminals exist in the LSO and each may contain amino acid transmitters (Helfert et al., '88b, '89a).

This study was undertaken to correlate the structure and neurotransmitter specificity of the inputs to LSO neurons with their function in sound localization. To accomplish this, postembedding immunoelectron microscopy was used to detect and quantify immunolabeling for the three amino acids (glutamate, glycine, and GABA) that are likely to be involved in neurotransmission at LSO synapses. The results reveal the presence of four classes of synaptic terminals in the LSO. Each can be distinguished from the others morphologically and by a distinct pattern of immunolabeling for glutamate, glycine, and GABA. In addition, each exhibits a characteristic distribution on LSO neurons. The relationships between morphology and transmitter immunolabeling in the synaptic terminals providing input to the
LSO observed here are similar to those described in other areas of the brain. The synaptic architecture of the LSO correlates well with its function, as discussed below.

\section{MATERIALS AND METHODS Tissue preparation}

Five pigmented guinea pigs (200-300 g, NIH strain) were used in this study. They were deeply anesthetized with pentobarbital, exsanguinated transcardially with $0.01 \%$ sodium nitrite in physiological saline, and perfused over a 15 minute time period with $750 \mathrm{ml}$ of fixative containing $1.25 \%$ glutaraldehyde and $1.0 \%$ paraformaldehyde in 0.12 $\mathrm{M}$ sodium phosphate buffer, $\mathrm{pH}$ 7.4. The brainstems were removed, stored overnight at $4^{\circ} \mathrm{C}$ in $0.12 \mathrm{M}$ phosphate buffer and then sectioned at $150 \mu \mathrm{m}$ in the transverse plane with an oscillating tissue slicer (Vibrotome ${ }^{(i)}$ ). After washes in $0.15 \mathrm{M}$ sodium cacodylate buffer, $\mathrm{pH} 7.4$, the sections containing auditory nuclei were postfixed for 45 minutes in $0.2 \%$ osmium tetroxide, stained en bloc with uranyl acetate (Karnovsky, '67), dehydrated through a graded ethanol series and propylene oxide, and flat-embedded in EMbed 812-based resin (Electron Microscopy Sciences, Fort Washington, PA).

\section{Postembedding immunocytochemistry}

Under a stereomicroscope (Wild M8), the LSO was dissected from the embedded tissue and mounted on blank resin blocks. Sections of the LSO were cut at $85 \mathrm{~nm}$ with an ultramicrotome (Reichert Ultracut) and collected serially on 400 mesh nickel grids ( 1 or 2 sections per grid). To unmask antigenicity, osmium was bleached from the sections by placing the grids in aqueous $1 \%$ sodium metaperiodate for 20 minutes, followed by a distilled water $\left(\mathrm{dH}_{2} \mathrm{O}\right)$ rinse. The sections were then pretreated with a blocking solution of $25 \%$ normal goat serum (NGS) in 300-310 mOsm phosphate-buffered saline (PBS) with $0.3 \%$ Triton X-100 (PBS-TX) and incubated in a humidified chamber at room temperature for 18-24 hours in a primary antibody solution. The antibody solution contained one of the following affinity-purified, polyclonal rabbit antisera to amino acid conjugates: anti-glycine (Wenthold et al., '87) diluted 1:100-1:200, anti-GABA (Wenthold et al., '86) diluted 1:250-1:300, or anti-glutamate (Montero and Wenthold, '89) diluted 1:200-1:300. The antibody dilutions were made using $5 \%$ NGS in PBS-TX as the diluent. To assess coimmunolabeling for glutamate, glycine and/or GABA in individual synaptic terminals, each of three serial sections were incubated in a different one of the three antisera dilutions. After a PBS rinse, the primary antibody was tagged by treating the sections with goat anti-rabbit IgG-coated $\mathbf{1 5}$ $\mathrm{nm}$ colloidal gold (Amersham, Arlington Heights, IL) diluted 1:10 in PBS-TX. Finally, the sections were rinsed with $\mathrm{dH}_{2} \mathrm{O}$, stained with uranyl acetate and lead citrate, and examined with a JEOL 1200 electron microscope.

For morphological classification, the size and shape of the synaptic terminal profiles, the shapes of their vesicles and the symmetry of their synaptic specializations were determined on electron micrographs at $\times 20,000$ to $\times 50,000$ magnification. The size of synaptic vesicles and the synaptic clefts were measured in 25 representative synaptic terminal profiles at $\times 200,000$ magnification. Vesicles were assigned to one of three shape categories based on ratios of the lengths of their minor and major axes. Vesicles with minor axes equal to or less than one-half the length of their major 


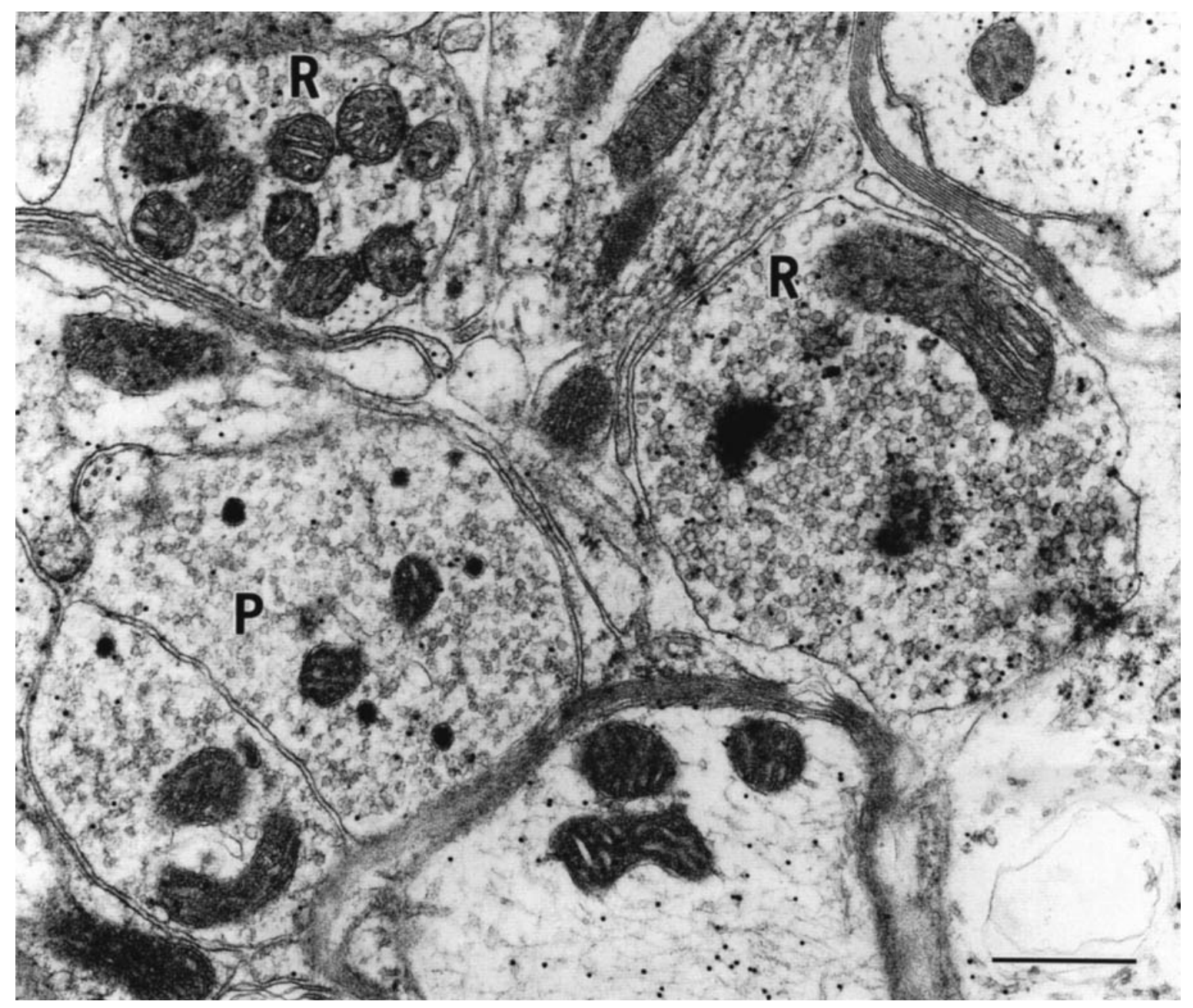

Fig. 1. Electron micrograph of immunogold labeling for glutamate. The electron-dense colloidal gold particles tag the immunoreactive sites. Round-vesicle terminals $(R)$ possess a higher density of colloidal gold label than terminals containing small pleomorphic vesicles $(\mathrm{P})$. Bar $=0.5 \mu \mathrm{m}$.

axes (ratio $\leq 0.5$ ) were categorized as flattened, while those that were as wide as they were long (ratio $=0.9-1.0$ ) were considered to be round in shape. Vesicles classified as oval had ratios between those of round and flattened vesicles $(0.5-0.9)$. Round vesicles could be further classified on the basis of electron density. They were either clear (electron lucent) or granular (contained an electron-dense core). Flat and oval vesicles were exclusively clear. Terminals were classified as round vesicle types when they contained almost exclusively round vesicles, pleomorphic vesicle types when they contained vesicles that ranged from round to oval (1.0-0.5) and flattened vesicle types when they contained vesicles that varied in shape from round to flat $(1.0-<0.5)$. In the latter type, typically $>20 \%$ of the vesicles were flattened. For the assessment of symmetry, synapses with paramembranous thickenings of similar thickness were classified as symmetric, while those in which the postsynaptic densities were at least twice as thick as the presynaptic ones were categorized as asymmetric.

\section{Quantitation of immunoreactive labeling}

In two of the five animals, immunocytochemical labeling was evaluated quantitatively to determine if the perceived differences in glutamate, GABA, or glycine immunogold labeling densities among the different synaptic terminal types were statistically significant. In each of the animals, three serial grids were assessed. One grid contained sections immunolabeled for glutamate, while the other two possessed sections immunolabeled for GABA and glycine, respectively. Quantitative comparison of the density of colloidal gold particles in different terminal types was performed on montages constructed from electron micrographs enlarged to a final magnification of $\times 37,500$. Two or 3 montages were obtained from each grid. Typically, each montage represented approximately $1,350 \mu \mathrm{m}^{2}$ of uninterrupted LSO field. The density of colloidal gold particles was measured over synaptic terminals classified into different morphological types based on several criteria, including size and shape of the synaptic terminal types, size and shape of their synaptic vesicles and, when available, number and morphology of their synaptic zones. Terminals that could not be classified using at least two of these criteria (e.g., terminals with very few vesicles and no discernible synaptic specialization) were omitted from the study. Perimeters of the defined terminal or glial profiles were traced on a digitizing tablet and all gold particles (including those over 


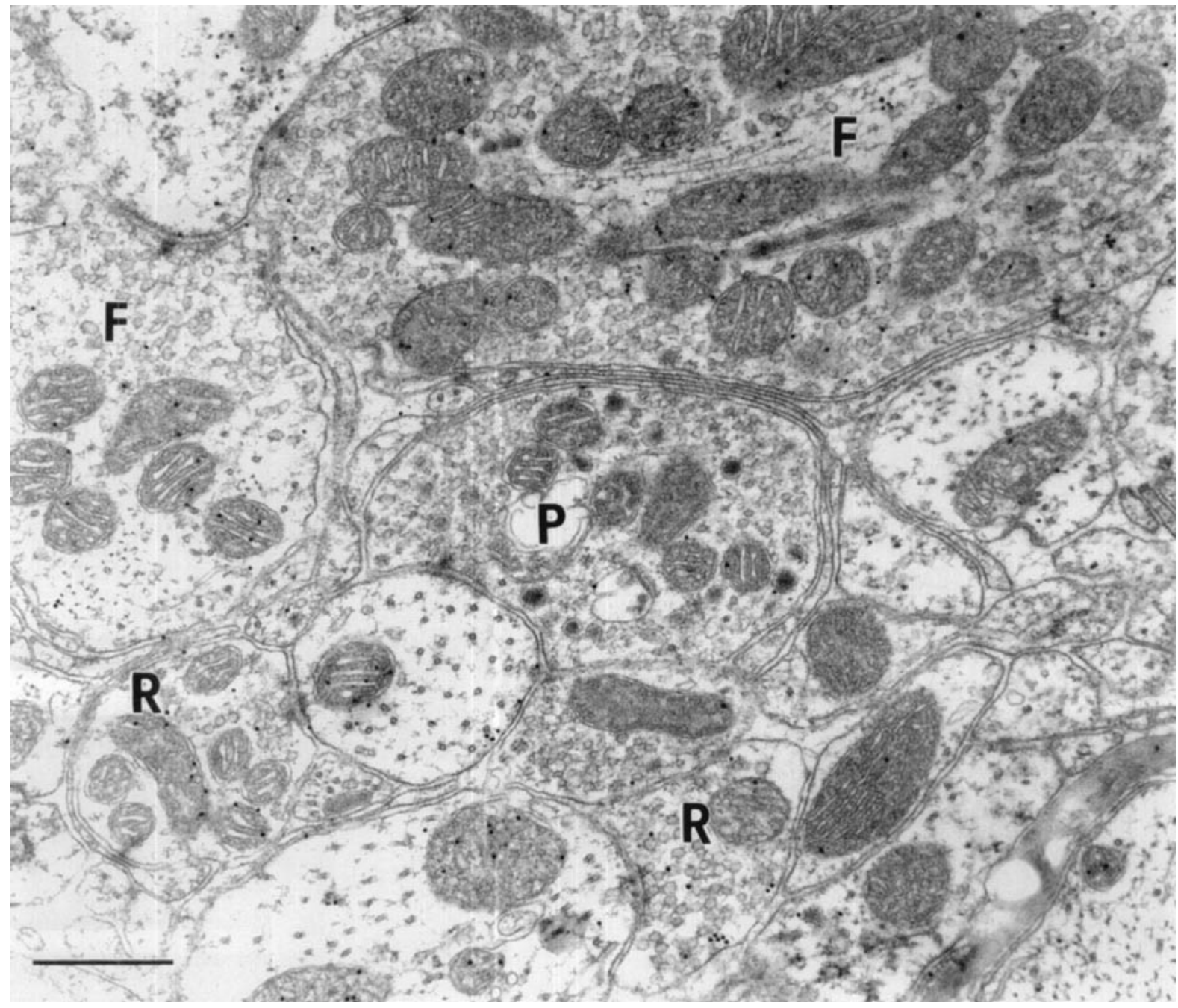

Fig. 2. Electron micrograph of immunoreactive labeling for glutamate. Presynaptic terminals containing flattened vesicles (F) have a higher density of immunogold label than those containing smal pleomorphic vesicles (e.g., P). R, round-vesicle terminals. Bar $=0.5 \mu \mathrm{m}$.

mitochondria) were counted by an observer unaware of the purpose of the experiment. Gold particles located over plasma membranes were not counted, and when aggregates of two or more gold particles were encountered, they were counted as a single particle. The area of each profile and its density of colloidal gold labeling (expressed as particles/ $\mu \mathrm{m}^{2}$ ) was determined from the digitized images using software designed in-house. The mean densities and standard errors of the means for each synaptic type were calculated and compared statistically with those obtained from the other types by running ANOVAs with pairwise comparisons, using Bonferroni's correction for multiple groups.

\section{Immunocytochemical controls}

As controls for the specificity of the antisera, sections were incubated in the different primary antisera preadsorbed with the amino acid conjugate against which each was raised. Immunolabeling was abolished in each instance. However, preadsorption of each antisera with the other conjugates (i.e., preadsorption of anti-glutamate with glycine or GABA conjugates, anti-GABA with glycine or glutamate conjugates, or anti-glycine with GABA or glutamate conjugates) had no noticeable effect on its specificity. To evaluate the specificity of the detection method, sections were processed as described above, except that they were incubated in 5\% NGS in PBS-TX without primary antisera. Colloidal gold immunolabeling was absent in these cases.

\section{RESULTS \\ Synaptic terminal types and their distribution on LSO neurons}

Four types of synaptic terminals were distinguishable from one another morphologically and on the basis of their unique patterns of immunolabeling for glutamate, GABA, and glycine. These patterns could be identified both subjectively (Figs. 1-11) and quantitatively (Fig 12, Table 1). Because they could be identified with relative ease by 


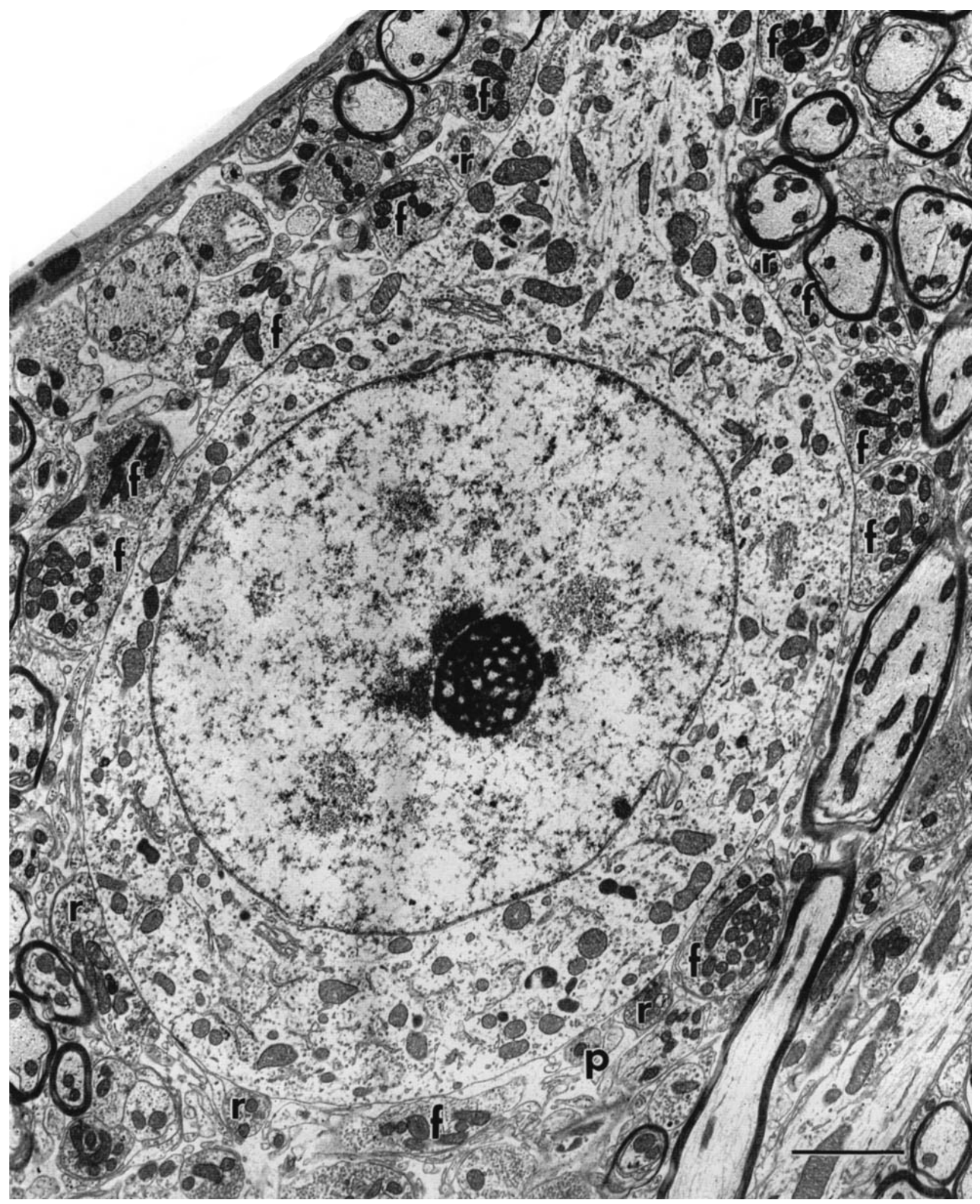

Fig. 3. Electron micrograph showing the distribution of synaptic terminals on an LSO principal neuron. The terminals contacting this neuron were classified at a higher magnification. Terminals containing flattened vesicles ( $f$ ) predominate over those that contain round $(r)$ or pleomorphic $(p)$ vesicles. Bar $=2 \mu \mathrm{m}$. 


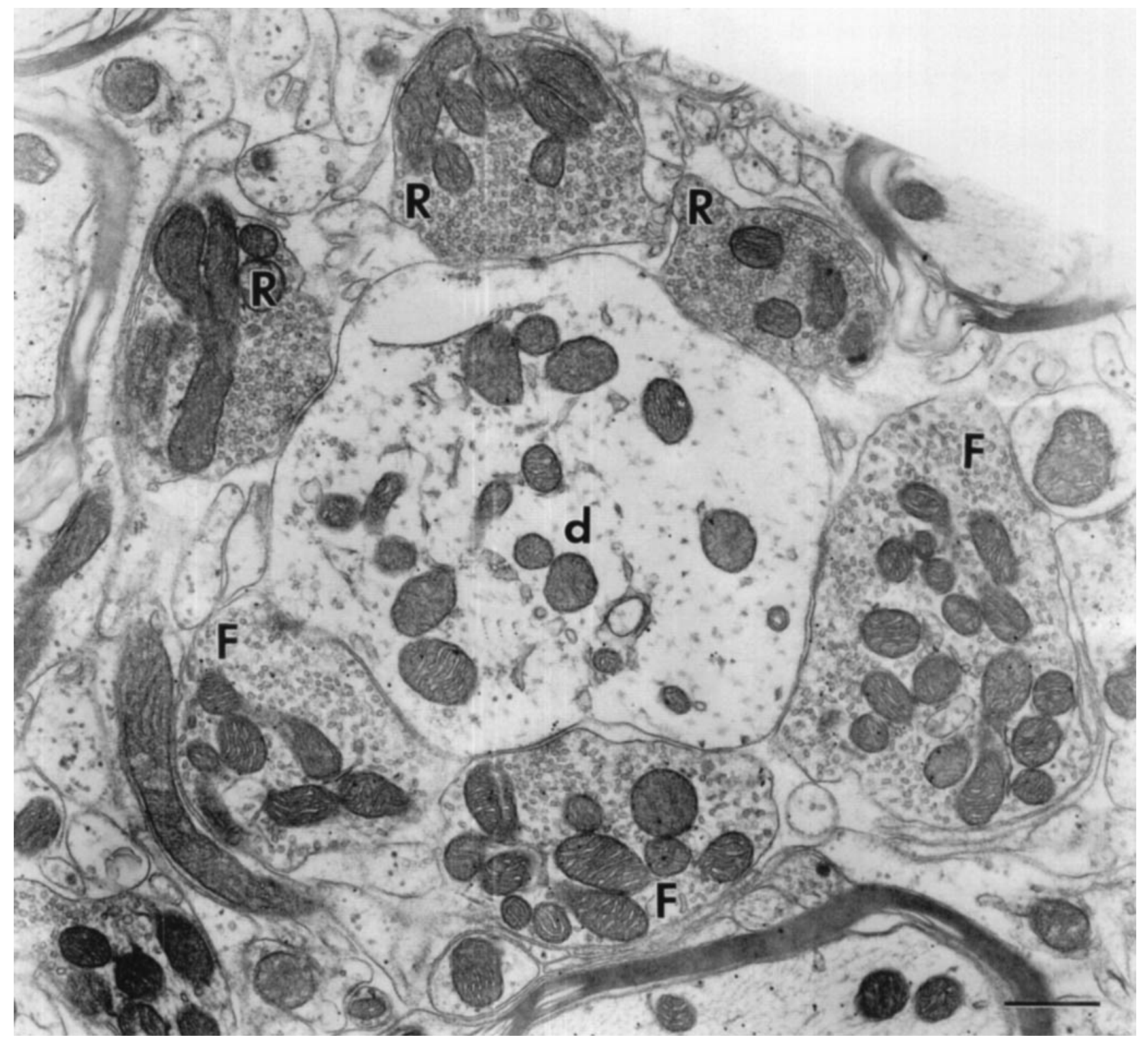

Fig. 4. Electron micrograph showing the distribution of glycineimmunolabeled synaptic terminals on a large dendrite (d). Terminals containing flattened $(F)$ vesicles possess a higher density of immunogold labeling for glycine than those with round $(R)$ vesicles. Both

differences in the size, shape and electron density of their synaptic vesicles, the terminal types were named according to their vesicle type as round-vesicle $(R)$, flattened-vesicle (F) and pleomorphic-vesicle (P) terminals. The $\mathrm{P}$ terminals were further categorized by vesicle size as either small (SP) or large (LP).

Round-vesicle terminals varied in size from $1-1.5 \mu \mathrm{m}$ in height and $1-5 \mu \mathrm{m}$ in length. They were typically round or dome-like in shape and possessed a single active zone when observed on somata and cross-sectioned dendrites (Figs 1, $2,4-8,10,11)$. Occasionally they were elongated and formed multiple synaptic contacts, particularly when ob- types occupy most of the surface of $d$. Typically, $R$ and $F$ terminals contact dendrites of this size in roughly equal proportions, as shown here. Bar $=0.5 \mu \mathrm{m}$.

served on obliquely or longitudinally sectioned dendrites. The vesicles in $R$ terminals were clear and uniform in size, with the vast majority measuring $40 \mathrm{~nm}$ in diameter. A very small number were either smaller $(\sim 35 \mathrm{~nm}$ ) or larger (up to $50 \mathrm{~nm}$ ). The paramembranous densities associated with the active zones of $R$ terminals were asymmetric, and their pre- and postsynaptic membranes were separated by a distance of between 25 and $30 \mathrm{~nm}$.

Flattened-vesicle terminals (Figs. 2, 4-6, 8, 10, 11) were $1-1.5 \mu \mathrm{m}$ in height and $2-5 \mu \mathrm{m}$ in length. In general, they were a little longer than $R$ terminals and each formed one or two synaptic contacts. The widest variety of vesicle shapes 


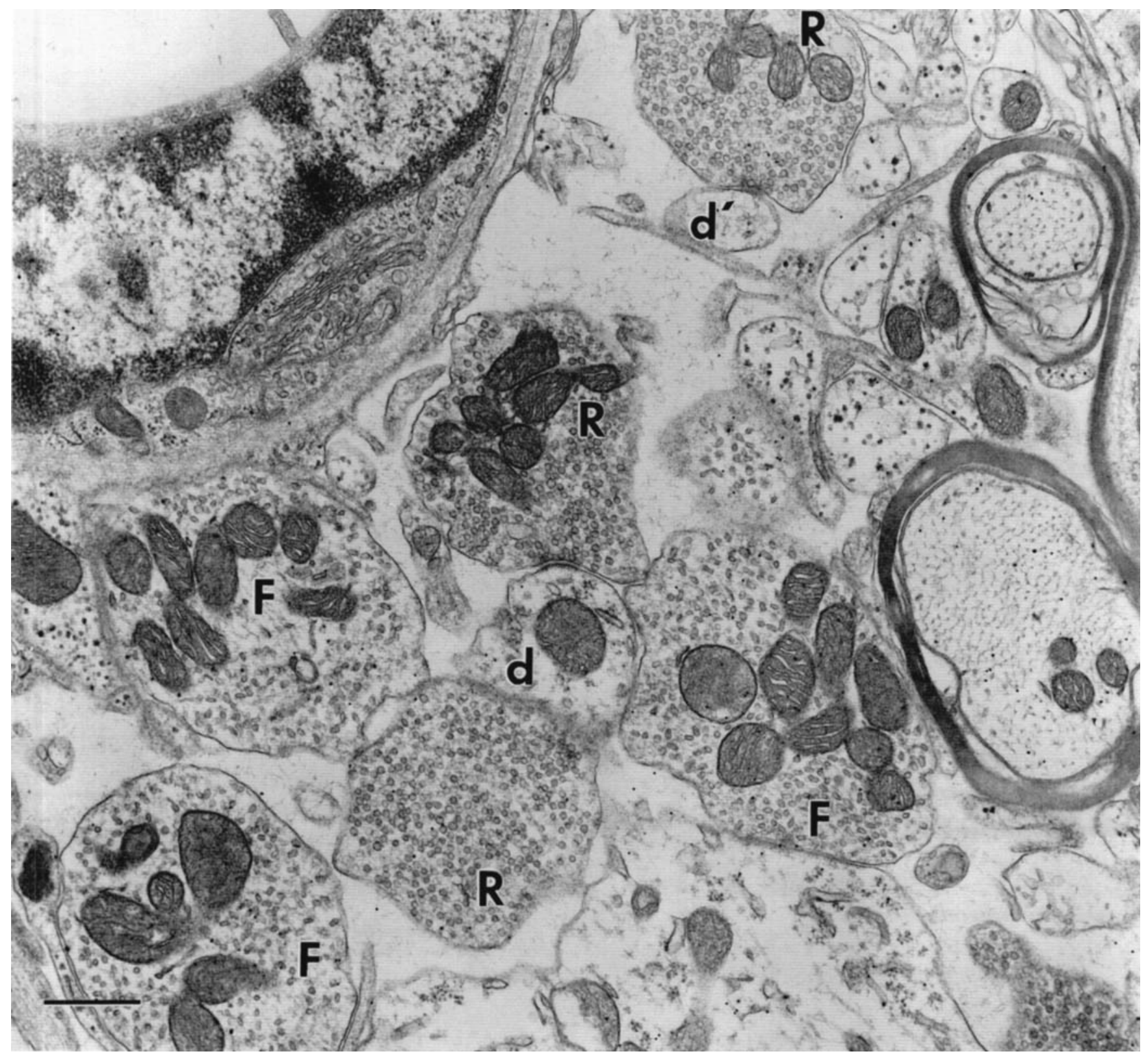

Fig. 5. Electron micrograph illustrating the distribution of glycine-immunolabeled synaptic terminals on thin dendrites $\left(d, d^{\prime}\right)$. The immunolabeling for glycine is greater over the terminals containing flattened vesicles $(F)$ than over those that contain round vesicles $(R)$. On thin dendrites, $R$ terminals outnumber $F$ terminals. Bar $=0.5 \mu \mathrm{m}$.

and dimensions were encountered in $\mathrm{F}$ terminals. The flattened vesicles possessed major axes ranging from 50 to $60 \mathrm{~nm}$ in length. The remainder of the vesicles were either oval, measuring $40-50 \mathrm{~nm}$ in length, or round, $35-45 \mathrm{~nm}$ in diameter. The pre- and postsynaptic densities were symmetric and were separated by a synaptic cleft measuring $20 \mathrm{~nm}$.

The profiles of most of the perikarya and dendrites were surrounded by presynaptic terminals, and the $\mathrm{R}$ and $\mathrm{F}$ terminals were the types most frequently encountered. The only somal profiles that appeared to be devoid of synaptic contacts were those belonging to small neurons, which were probably neurons of the lateral olivocochlear system (Helf- ert et al., ' $88 \mathrm{a}$ ). The distribution of $\mathrm{R}$ and $\mathrm{F}$ terminals on most LSO neurons appeared to follow gradients that ran opposite to one another. On the perikarya of principal neurons, $F$ terminals predominated over both $R$ and $P$ terminals by a ratio of $\geq 2: 1$ (Fig. 3 ). On dendrites with calibers greater than $3 \mu \mathrm{m}, \mathrm{F}$ and $\mathrm{R}$ terminals were found in roughly equal proportions (e.g., Fig. 4), while on dendrites of diameters approaching $1 \mu \mathrm{m}, \mathrm{R}$ terminals prevailed over the others by a ratio of approximately $2: 1$ (e.g., Fig. 5). The smallest dendrites (diameters $\leq 0.5 \mu \mathrm{m}$ ) were normally contacted by $\mathrm{R}$ or SP terminals, but not by $\mathrm{F}$ or $\mathrm{LP}$ terminals. 


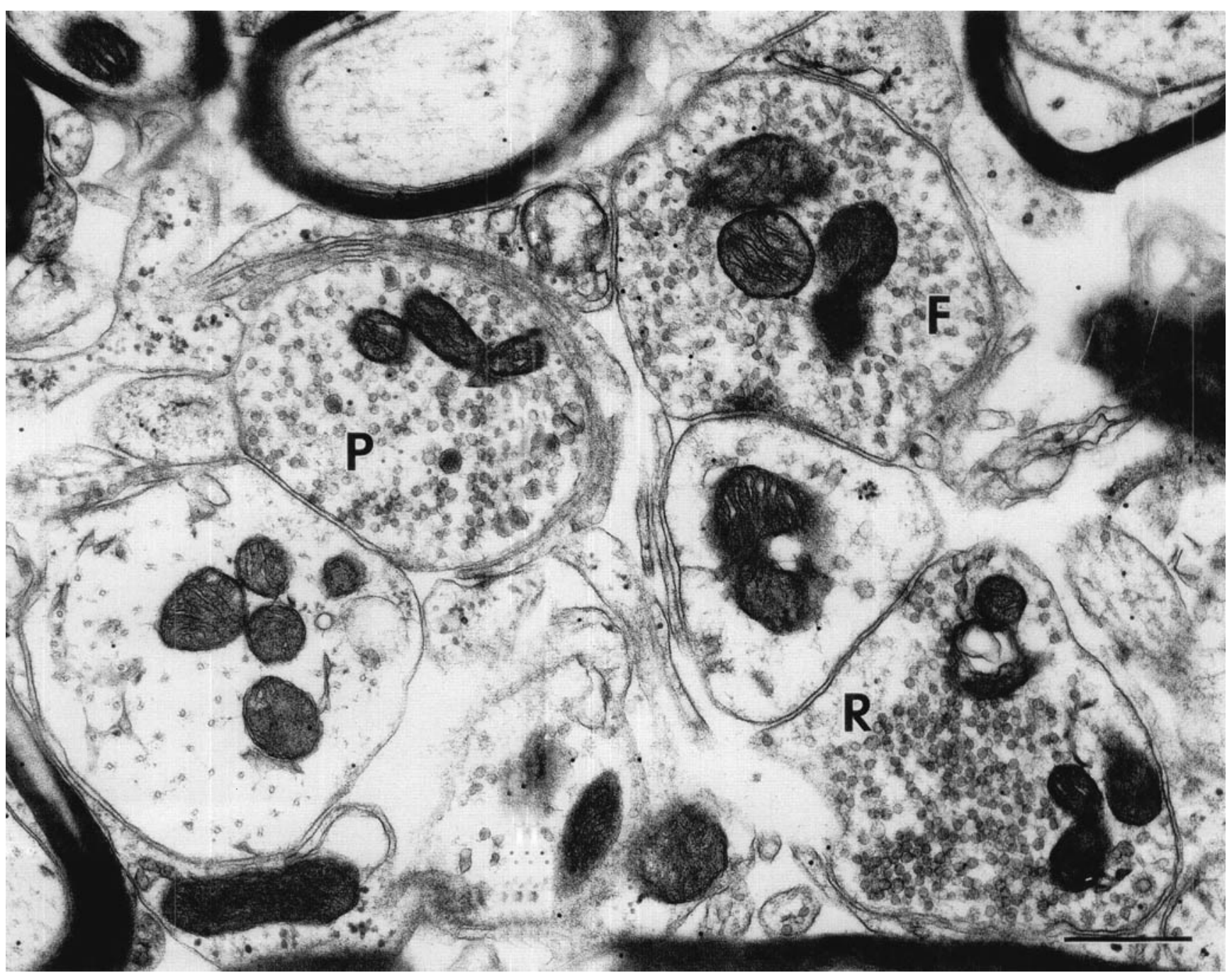

Fig. 6. Electron micrograph of immunolabeling for glycine. The presynaptic terminal with flattened vesicles $(F)$ contains a higher density of immunogold labeling than that found over both round $(R)$ - and small pleomorphic $(\mathrm{P})$-vesicle terminals. Bar $=0.5 \mu \mathrm{m}$.

Pleomorphic-vesicle terminals were encountered less frequently than $\mathrm{R}$ and $\mathrm{F}$ terminals. The LP and SP terminals were similar to each other in that they typically contacted the postsynaptic membrane with a single synaptic junction, their synaptic specializations were symmetric, their synaptic clefts measured $25 \mathrm{~nm}$ in width and most of the vesicles contained in these terminals were either oval or round. However, the two types differed in three ways. First, LP terminals (Figs. 7, 9,11) were larger, usually 1 to $2 \mu \mathrm{m}$ in both height and length, while SP terminals (Figs. 1, 2, 6, $8-10$ ) were usually $\leq 1 \mu \mathrm{m}$ in either dimension. Second, the agranular vesicles in LP terminals were significantly larger $(40-50 \mathrm{~nm})$ than those of SP terminals $(30-35 \mathrm{~nm})$. Third, SP terminals usually contained several granular vesicles $75-110 \mathrm{~nm}$ in diameter in addition to the clear ones. Granular vesicles were normally absent in the LP terminals and, if present, were few in number.

Both LP and SP terminals were similar in that both were scattered in small numbers throughout the LSO. However, while there was some overlap in their distribution on LSO neurons, LP terminals were most frequently observed contacting somata, dendritic trunks and dendrites with diameters greater than $1 \mu \mathrm{m}$, while SP terminals normally contacted smaller caliber $(\leq 1 \mu \mathrm{m})$ dendrites, often in pairs.

\section{Glutamate, GABA, and glycine immunolabeling patterns in the four terminal types}

With few exceptions, $\mathrm{R}$ terminals labeled intensely for glutamate (Figs. 1, 2), but not for GABA or glycine (Figs. 4-11). Flattened-vesicle terminals exhibited strong immunoreactivity for both glycine (Figs. 4-6, 10) and glutamate (Figs. 2, 10), but not for GABA (Figs. 8, 10). Both LP and SP terminals shared in common intense GABA immunoreactivity (SP terminals, Figs. 8-10; LP terminals, Figs. 9, 11 ), and reduced glutamate immunolabeling (SP terminals, Figs. 1, 2, 10; LP terminals, Fig. 11). However, the latter two terminal types differed in that LP terminals also 


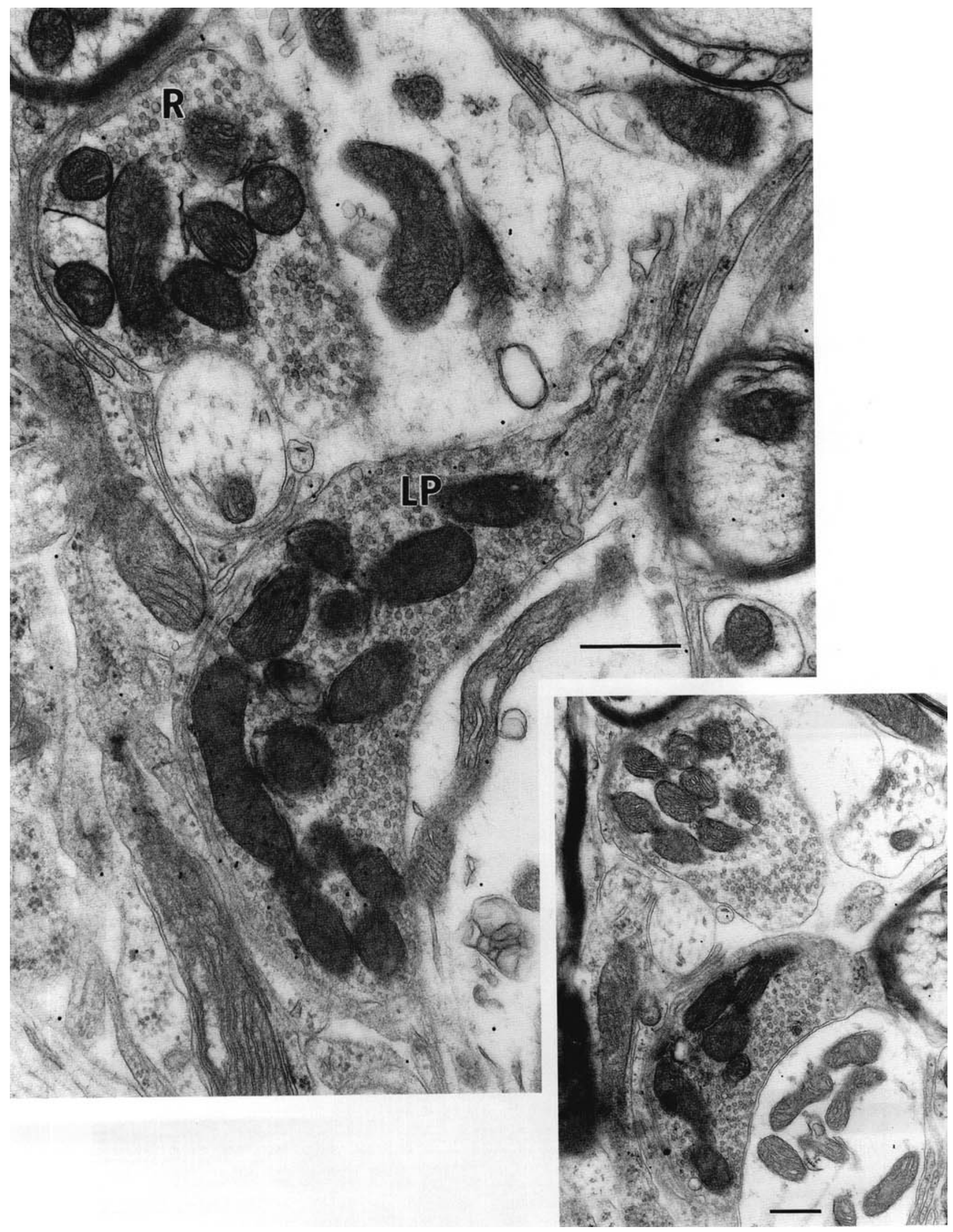

Fig. 7. Electron micrographs of a presynaptic terminal containing large pleomorphic vesicles (LP) immunolabeled for glycine, while in a semi-adjacent section (inset), the same terminal is immunopositive for GABA. The terminal with round vesicles $(\mathrm{R})$ does not label above background for either antigen. Bar = $0.5 \mu \mathrm{m}$. 


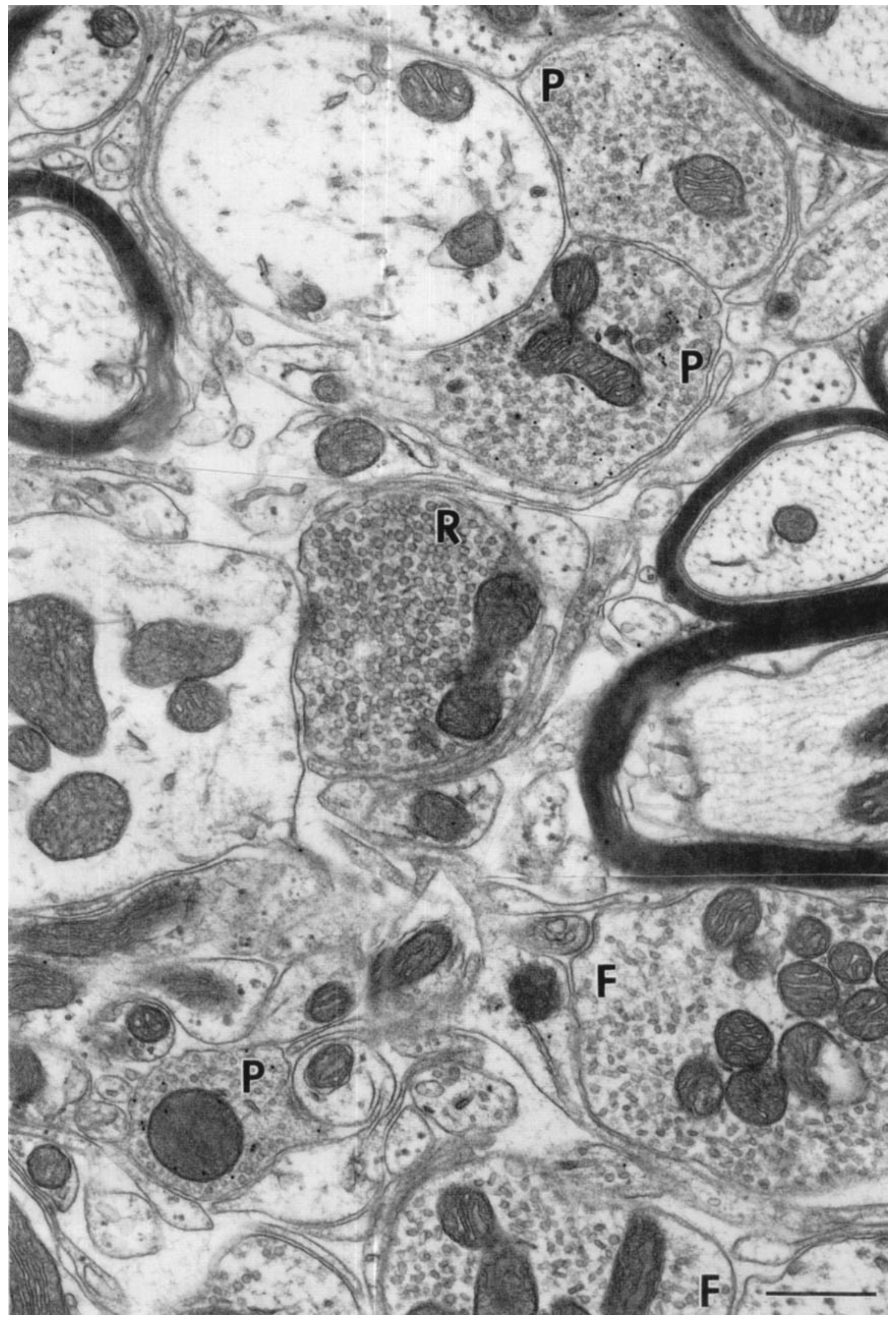

Fig. 8. The terminals containing small pleomorphic vesicles $(\mathrm{P})$ are immunopositive for GABA, while the terminals with round $(\mathrm{R})$ and flat $(\mathrm{F})$ vesicles are not. Bar $=0.5 \mu \mathrm{m}$ 


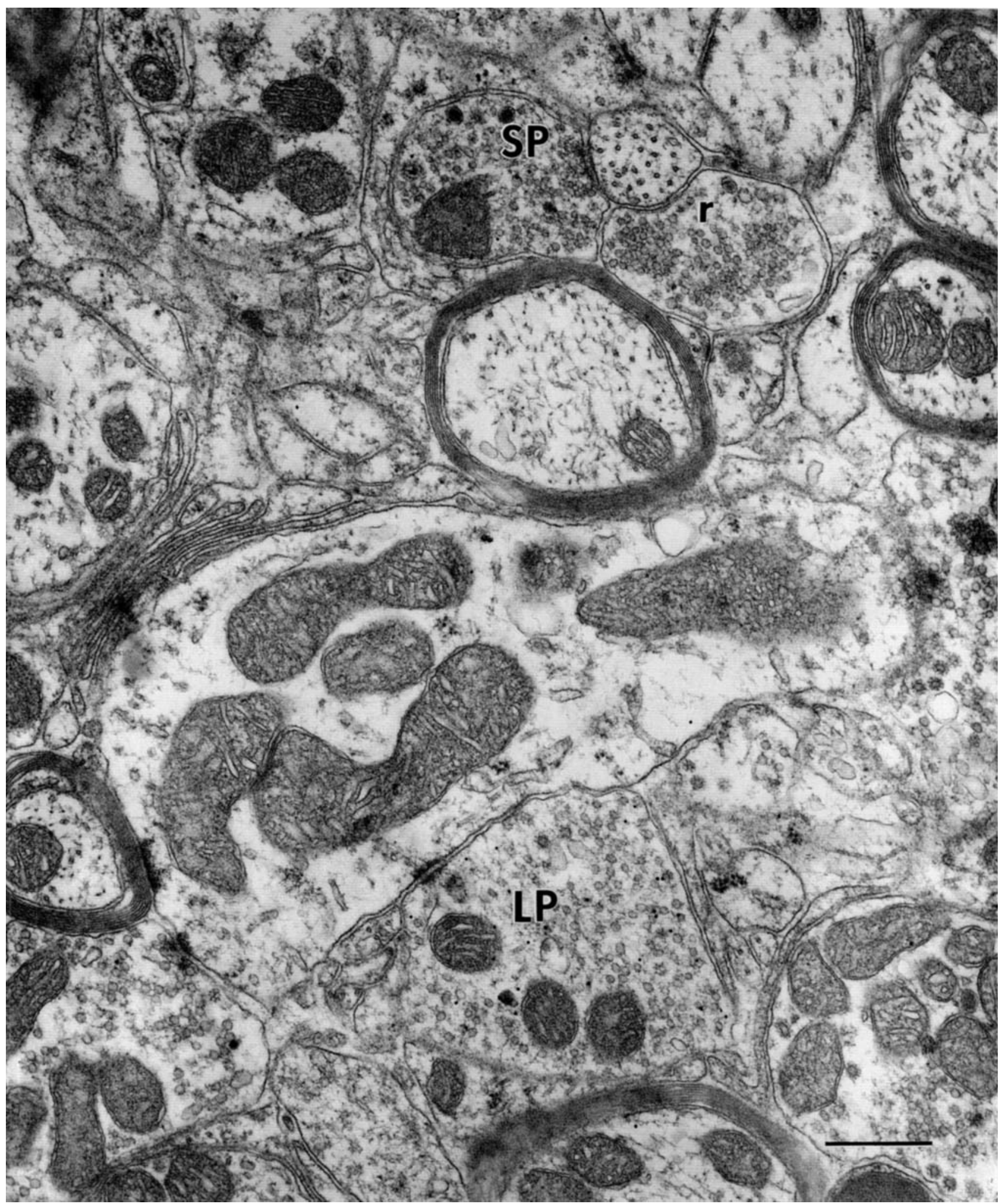

Fig. 9. Electron micrographs of immunolabeling for GABA. The terminals containing small pleomorphic vesicles (SP) and large pleomorphic vesicles (LP) exhibit enriched immunolabeling for GABA. The terminal with small, round vesicles $(r)$ is not labeled. Bar $=0.5 \mu \mathrm{m}$. 

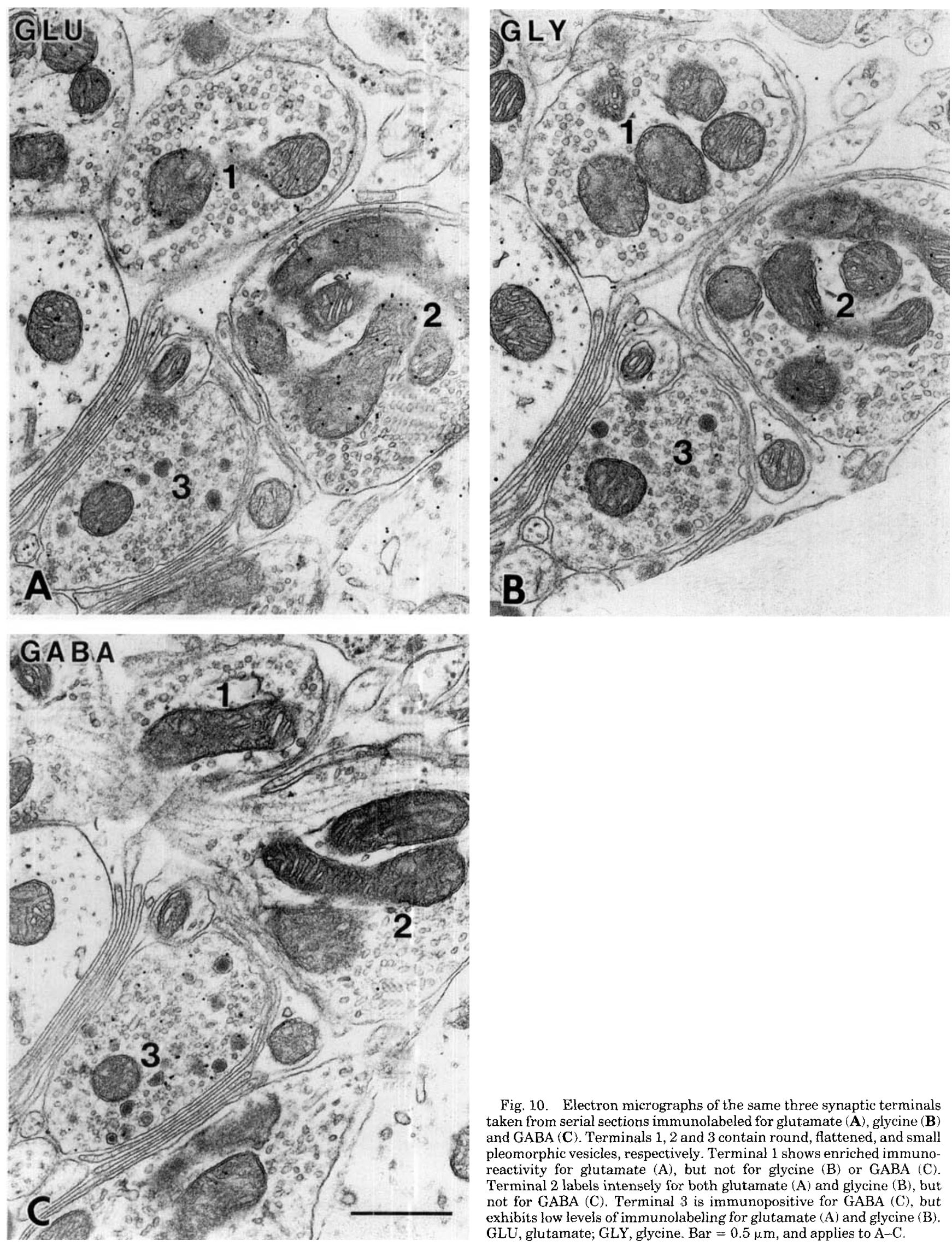

Fig. 10. Electron micrographs of the same three synaptic terminals taken from serial sections immunolabeled for glutamate $(\mathbf{A})$, glycine $(\mathbf{B})$ and GABA $(\mathbf{C})$. Terminals 1, 2 and 3 contain round, flattened, and small pleomorphic vesicles, respectively. Terminal 1 shows enriched immunoreactivity for glutamate (A), but not for glycine (B) or GABA (C) Terminal 2 labels intensely for both glutamate (A) and glycine (B), but not for GABA (C). Terminal 3 is immunopositive for GABA (C), but exhibits low levels of immunolabeling for glutamate $(A)$ and glycine $(B)$. GLU, glutamate; GLY, glycine. Bar $=0.5 \mu \mathrm{m}$, and applies to A-C. 
labeled intensely for glycine (Figs. 7,11 ), while SP terminals did not (Figs. 6, 10).

The quantitative immunocytochemical data supported the descriptive observations. Figure 12 shows the mean densities of immunogold labeling for glutamate, GABA, and glycine over the different terminal types in two animals, while the statistical comparisons of these means can be found in Table 1 . Because of the close similarity in their levels of glutamate and GABA immunogold densities, the data from LP and SP terminals were combined to form a single group ( $P$ terminals) on the graphs representing glutamate and GABA.

In both animals, the density of immunogold labeling for glutamate in $R$ terminals was approximately four and one-half times that measured over glial cytoplasm. The density of glutamate immunolabeling in $\mathrm{F}$ terminals was approximately three times that in glia, and in $\mathrm{P}$ terminals, two times greater. The levels of glycine immunoreactivity were approximately three times higher in F and LP terminals than in $\mathrm{R}$ terminals, SP terminals or glia. Immunogold labeling for GABA over P terminals was at least 20 times greater than that over any of the other types. The level of GABA immunolabeling over $P$ terminals appeared high because of the uniformly low levels measured over $R$ terminals, $F$ terminals and glial cytoplasm.

In general, the colloidal gold labeling over all immunopositive terminals was high over mitochondria as well as extravesicular spaces. This was not the case with terminals that exhibited little or no immunoreactive labeling. While it is conceivable that the labeling over these areas in immunolabeled terminals may reflect actual disparities in amino acid content in the mitochondria and extravesicular space among the different terminal types, a more plausible possibility relates to changes that may be associated with the methodology. The antibodies, which were raised against amino acids conjugated to a large protein (bovine serum albumin) with glutaraldehyde, could have recognized antigens that were displaced from the vesicles during fixation and subsequently linked to large proteins in the extravesicular space, including mitochondrial proteins, by the glutaraldehyde contained in the fixative.

\section{Colocalization of immunolabeling for} neuroactive amino acids in $F$ and $L P$ terminals

That two of the terminal types could be tagged by more than one antisera was confirmed in the colabeling experiments. In the sections evaluated for coimmunolabeling of the antigens, high levels of both glutamate- and glycine-like immunoreactivity were found in the same population of $F$ terminals. An example is shown in Figure 10, which consists of micrographs of three adjacent or semiadjacent sections immunolabeled for glutamate, glycine and GABA, respectively, and each containing profiles of the same three synaptic terminals. The $\mathrm{F}$ terminal in this figure labels intensely for glutamate (Fig. 10A) and glycine (Fig. 10B), but not for GABA (Fig. 10C). The $\mathrm{R}$ terminal exhibits strong immunoreactivity for glutamate, but not glycine or GABA, and the SP terminal immunolabels for GABA, but not for glutamate or glycine.

LP terminals cocontain glycine and GABA-like immunoreactivity. The LP terminal shown in Figure 11 is immunopositive for both GABA (Fig. 11B) and glycine (Fig. 11C), but contains a lower level of glutamate immunolabeling when compared to both $R$ and $F$ vesicle terminals (Fig.
11A). As described in the previous paragraph, SP terminals were immunolabeled intensely for GABA only.

\section{DISCUSSION}

This study has identified four classes of synaptic terminals in the lateral superior olive. They differed from one another morphologically and cytochemically. Each morphological type possessed a characteristic distribution on LSO neurons. With few exceptions, each possessed a distinctive pattern of enriched glutamate, GABA, and glycine immunolabeling. Two of the terminal classes appear to cocontain two amino acid transmitters. One coimmunolabels for glutamate and glycine while the other is coimmunoreactive for glycine and GABA. Thus, this study provides evidence linking these neuroactive amino acids to specific populations of synaptic terminals, lending further support for their roles as neurotransmitters or neuromodulators mediating excitation and inhibition in the LSO.

Two of the types, the glutamate-immunoreactive $R$ terminals and the glycine/glutamate-immunopositive $\mathrm{F}$ terminals, predominated and most probably function to mediate the binaural input to LSO principal neurons. The remaining two types, the GABA-immunoreactive SP terminals and LP terminals, the latter cocontaining glycine immunoreactivity, were found in fewer numbers. The sources of the perikarya from which they arise and their roles in LSO function are unknown. Overall, the distribution of $R, F$, and $\mathrm{P}$ terminals in guinea pigs is remarkably similar to that described for their counterparts in cats (Cant, '84).

\section{Comparison of the synaptic classes with those described in other areas of the brain}

The ultrastructural features of all the synaptic classes described in this study are comparable to synaptic classes with similar immunolabeling patterns described elsewhere in the brain. The morphology of the $\mathrm{R}$ terminals observed in this study resemble that of the intensely glutamate immunolabeled terminals described in the cerebellum of cats (Somogyi et al., '86) and rats (Clements et al., '90), lateral geniculate nucleus of macaques (Montero and Wenthold, '89), hippocampus, spinal cord, and spinal trigeminal nucleus of rats (Clements et al., '90), cochlear nucleus of guinea pigs (Juiz et al., '89), periaqueductal gray-raphe magnus projection in rats (Beitz, '90), and spinal cord, cuneate nucleus and ventroposterolateral thalamic nucleus in rats (De Biasi and Rustioni, '90). They are similar to one another in that their vesicles are of the same size and shape; the synaptic specializations are asymmetrical (or type I as described in Gray, '59), and multiple synaptic contacts are often formed by a single terminal. In addition, the above studies suggest that glutamatergic terminals typically form axodendritic synapses, which is the case for $R$ terminals.

The quantitative results obtained from this study are comparable to those from investigations where the density of colloidal gold immunolabeling for glutamate was assessed over synaptic profiles. In the LSO, the density of glutamate immunolabeling over $\mathrm{R}$ terminals is twice that for P (GABA) terminals and four times that for glia. In the lateral geniculate nucleus, the excitatory retinogeniculate and corticogeniculate terminals contain round vesicles and form asymmetric synapses, and the immunolabeling for 

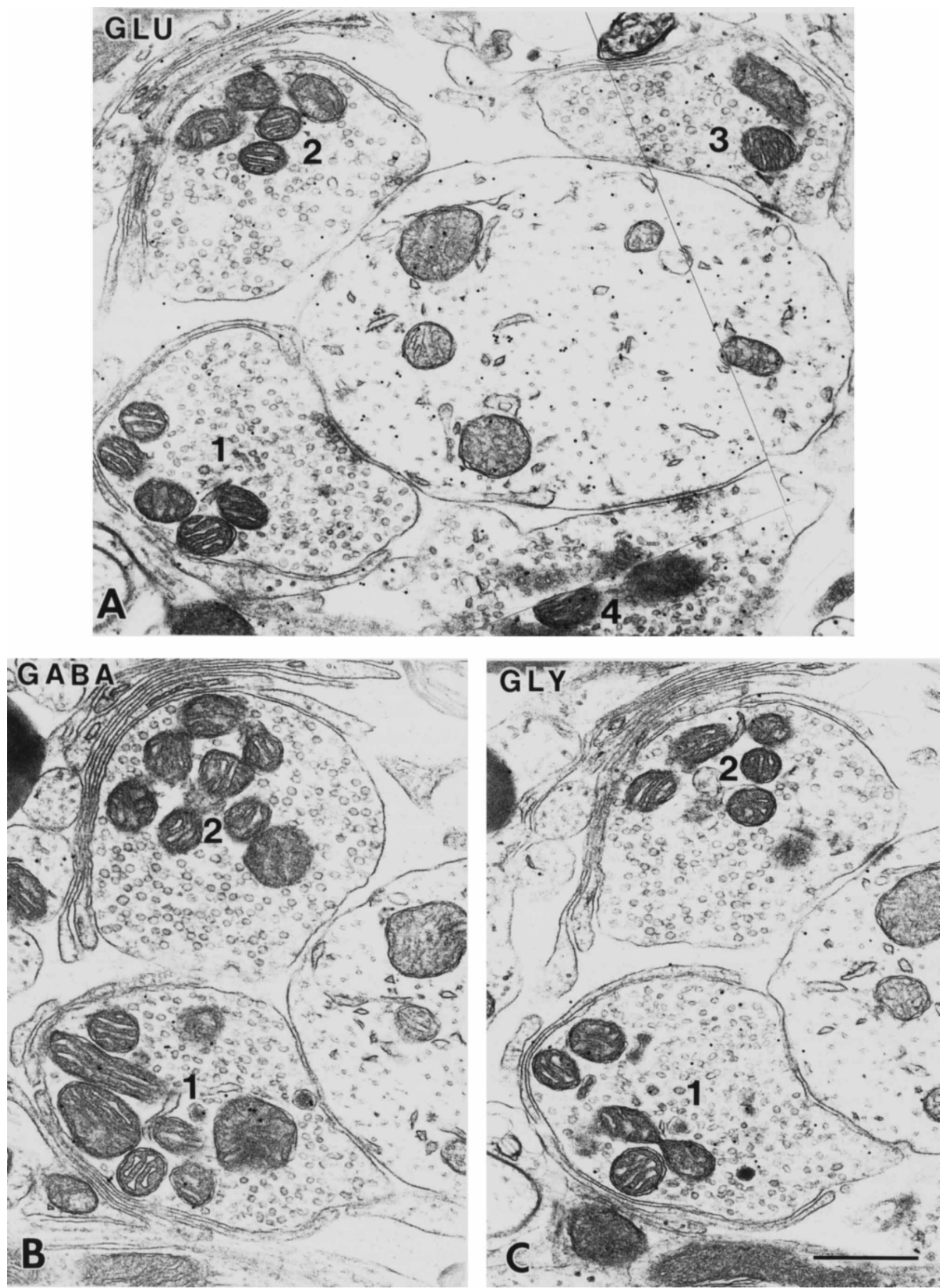

Figure 11 
R48

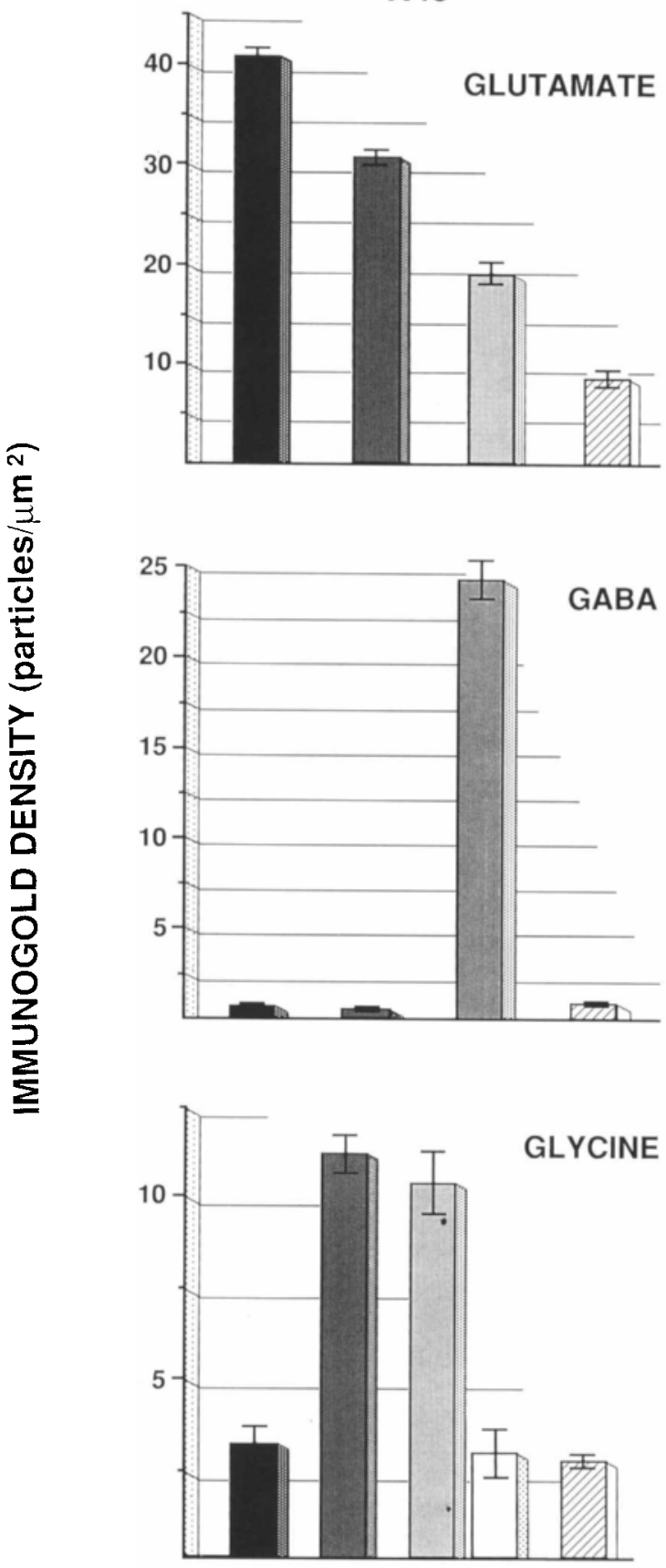

R58
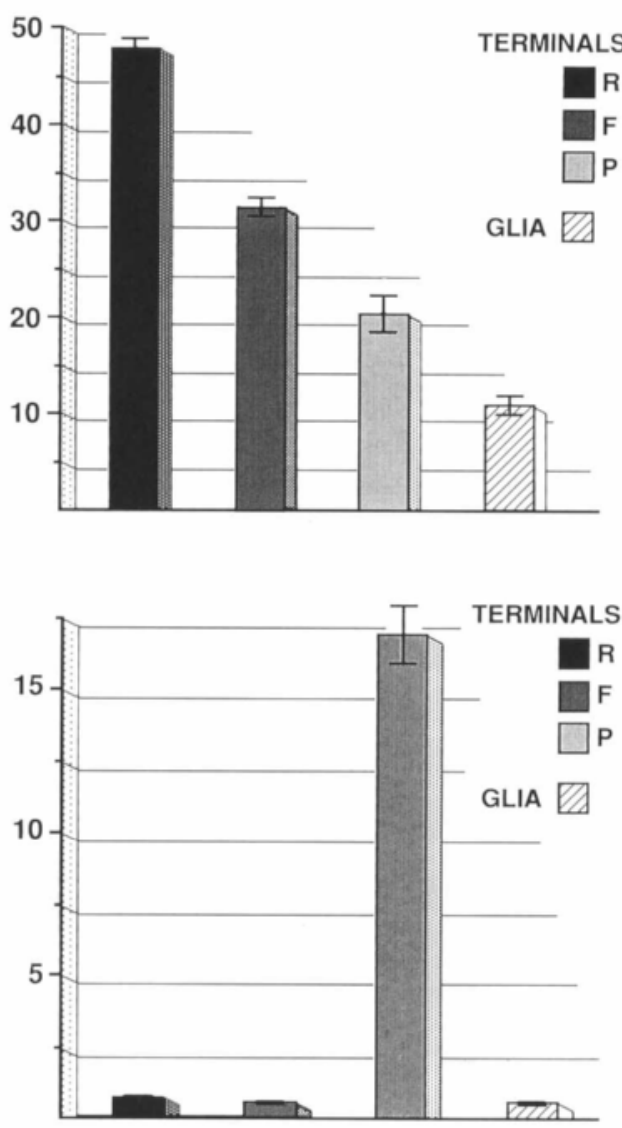

TERMINALS

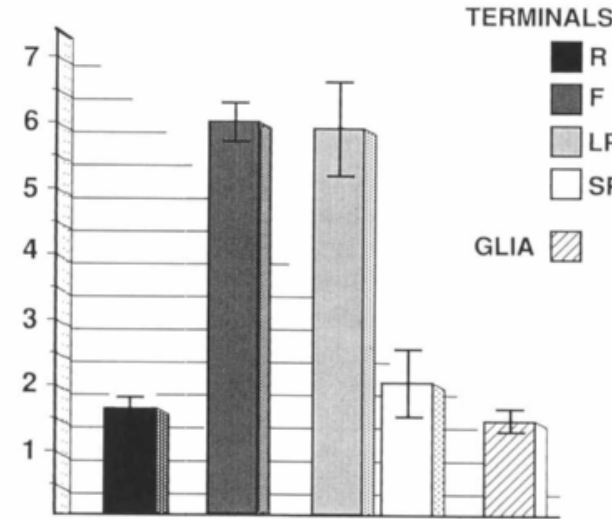

Fig. 12. Mean densities of immunogold labeling for glutamate, GABA, and glycine over the different terminal types and glia in two animals (R48 and R58). R, round-vesicle terminals; F, flattened-vesicle terminals; LP, large pleomorphic-vesicle terminals; SP, small pleomor-

glutamate over these terminals is 2 to 4 times greater than that over glia or pleomorphic vesicle (GABAergic) terminals (Montero and Wenthold, '89). In the cat cerebellum, the level of glutamate immunoreactivity over the excitatory, phic-vesicle terminals; P, SP and LP combined because of close similarities in glutamate and glycine immunolabeling. The statistical comparisons of these means can be found in Table 1 .

presumably glutamatergic mossy and parallel fiber terminals is at least twice that of the GABAergic Golgi cell terminals and 4 to 5 times greater than glutamate immunolabeling over glia (Somogyi et al., '86).
Fig. 11. Electron micrographs of the same synaptic terminals from serial sections immunolabeled for glutamate (A), GABA (B), and glycine $(\mathbf{C})$. Terminal 1 contains large pleomorphic vesicles, terminals 2 and 3 have round vesicles, and terminal 4 possesses flattened vesicles.
Terminals 2-4 exhibit higher levels of immunoreactive labeling than terminal 1. However, terminal 1 is immunopositive for both GABA (B) and glycine (C). GLU, glutamate, GLY, glycine. $\mathrm{Bar}=0.5 \mu \mathrm{m}$. 
TABLE 1. Statistical Comparison of Immunoreactive Synaptic Terminals

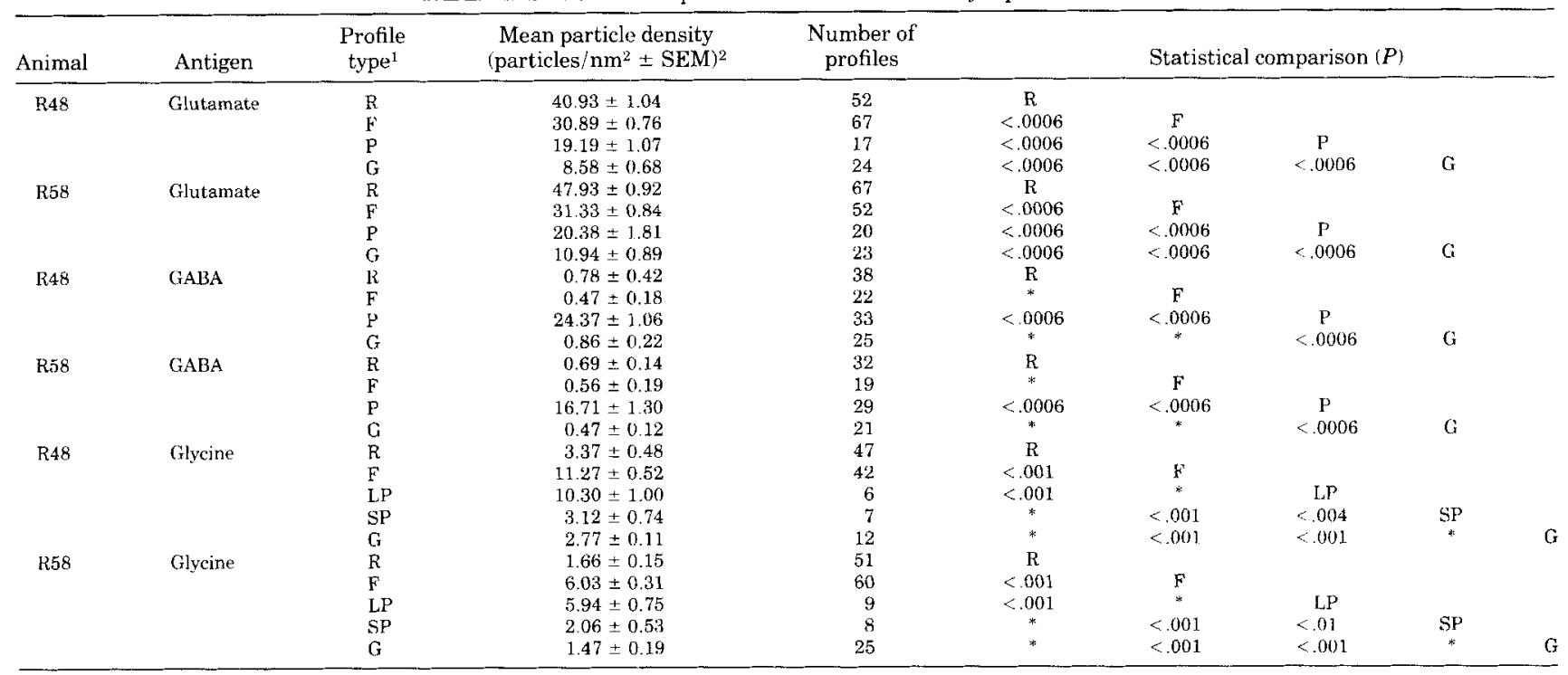

${ }_{\mathrm{R}}^{\mathrm{R}}$, round vesicle terminals; $F$, flat vesicle terminals; $L P$, large, pleomorphic vesicle terminals; $S P$, small plenmorphic vesicle terminals; $P$, large and small pleumorphic vesicle terminals combined; G, glia.

*Not significant $(P>20)$

Morphologically, terminals that contain glycine appear to form a more heterogeneous population in the central nervous system. In the guinea pig LSO, two populations of glycine-immunoreactive synaptic terminals can be identified: F (glycine/glutamate) and LP (glycine/GABA), both contacting perikarya and proximal dendrites with symmetric (type II) membrane specializations. Three different types of glycine-immunopositive boutons have been identified in the guinea pig cochlear nucleus (Altschuler et al., '89), all of which form symmetric junctions with the postsynaptic membranes. The types include flattened- and pleomorphic-vesicle terminals immunolabeled for glycine only, and pleomorphic-vesicle terminals cocontaining glycine and GABA. In the spinal trigeminal nucleus of rats, glycine-immunoreactive terminals synapse only on dendrites and axons (Clements et al., '90). They are small and contain round-to-oblong vesicles and either symmetric or asymmetric synaptic specializations. In the rat spinal cord, roughly one-half of glycine-immunoreactive terminals contain round vesicles and contact large dendrites with asymmetric membrane specializations, while most of the remainder possess flattened vesicles and synapse on perikarya with symmetric synaptic junctions (Clements et al., '90).

The SP terminals immunoreactive for GABA only are similar morphologically to those described in other areas of the brain (see Ribak and Roberts, ' 90 for review) in that they contain pleomorphic vesicles with or without densecore vesicles, and usually form symmetric synaptic junctions with their targets. They are also similar in appearance to terminals containing neuropeptides or catecholamines. The latter types contain pleomorphic and dense-core vesicles as well, but they typically form asymmetric synaptic specializations (see Maley, '90; Maley et al., '90 for reviews).

\section{Functional considerations}

As described above, LSO units are excited by ipsilateral sounds and are inhibited by the simultaneous presentation of similar contralateral sounds. Hence, they are thought to function in sound localization as comparators of interaural intensity and time differences. Indeed, the principal sources of input to the LSO reflect this function. The LSO derives most of its ipsilateral input directly from the bushy cells of the ipsilateral ventral cochlear nucleus (VCN) (Warr '66, '82; Cant and Casseday, '86). This pathway would convey the ipsilateral excitatory input to LSO neurons described in the electrophysiological studies. Most of the contralateral input to the LSO arises from bushy cells as well. However, this input is not direct. The medial nucleus of the trapezoid body (MNTB) is interposed between the VCN and the LSO in this pathway so that axons from bushy cells cross in the trapezoid body to terminate on the principal cells of the contralateral MNTB (Harrison and Warr, '62; Harrison and Irving, '64; Warr, '72; '82; Morest and Jean-Baptiste, '75; Tolbert et al., '82; Friauf and Ostwald, '88; Spirou et al., '90), which, in turn, project to the LSO ipsilateral to them (Rasmussen, '46; Harrison and Warr, '62; Elverland, '78; Glendenning et al., '85; Spangler et al., '85; Zook and DiCaprio, '88). The projection from the MNTB to the LSO is inhibitory (Sanes, '90; Wu and Kelly, '91) so that, in effect, the contralateral VCN inhibits LSO neurons by way of the MNTB. It has been proposed that this inhibition arrives via axosomatic synaptic terminals containing flattened vesicles (Cant, '84).

Evidence for glycine, glutamate, and GABA as neurotransmitters in the LSO. The observation of glycine-like immunoreactivity over $F$ and LP terminals in the LSO lends further support to the role of glycine as an inhibitory neurotransmitter in the LSO, as previously suggested in several studies. In chinchillas, the iontophoretic application of glycine on LSO neurons mimics contralaterally induced inhibition (Moore and Caspary, '83). Similar results have been obtained from in vitro studies with brain slices taken. through the mouse lower auditory brain stem (Wu and Kelly, '91). The inhibitory effect is abolished by the application of the glycine antagonist, strychnine (Moore and Caspary, '83; Wu and Kelly, '91). Sodium-dependent, high. 
affinity uptake of tritiated glycine has been demonstrated in two populations of terminals in the cat LSO (Schwartz, '85). Large terminals forming axosomatic synapses on principal cells comprised one population, while the other consisted of smaller terminals located in the neuropil. Immunocytochemical investigations with antibodies raised against subunits of the strychnine-sensitive glycine (glycine $_{1}$ ) receptor (Wenthold et al., '85) and binding studies with tritiated strychnine (Sanes et al., '87; Glendenning and Baker, ' 88 ) indicate the presence of an abundance of glycine $_{1}$ receptors in the LSO of cats, gerbils and guinea pigs. Glycine ${ }_{1}$ receptor-like immunoreactivity has been observed in LSO somata and dendrites postsynaptic to F terminals (Helfert, Juiz and Altschuler, unpublished observations in guinea pig). Quantitative neurochemical assays indicate that the cat LSO is enriched with glycine (Godfrey et al., ' 88 ). That the high levels of glycine in the LSO may be transmitter-related has been proposed by several immunocytochemical studies at the light microscopic level, which have shown that the LSO contains an abundance of punctate glycine-immunoreactive profiles surrounding many of its neural elements (in guinea pigs: Peyret et al., '87; Wenthold et al., '87; Helfert et al., '89a; in rats: Aoki et al., '88). The present study confirms that the glycine-immunolabeled puncta correspond to $\mathrm{F}$ and LP synaptic terminals, along with glycine-enriched axons.

Glutamate or a closely related substance may function in the LSO as an excitatory transmitter. The fast excitatory postsynaptic potentials evoked in the LSO by ipsilateral tone-burst stimuli are consistent with non-N-methyl-Daspartate (NMDA) excitatory amino acid receptor-mediated responses (Finlayson and Caspary, '89). The iontophoretic application of the non-NMDA receptor excitant amino acid (EAA) agonist quisqualate elicited a response in the LSO that mimics that induced by ipsilateral excitation (Caspary and Faingold, '89). EAA antagonists cis-2,3-piperidinedicarboxylic acid (PDA) and 6,7,-dinitroquinoxaline-2,3dione (DNQX) effectively blocked ipsilateral tone-evoked excitation in the chinchilla (Caspary and Faingold, '89) and electrically evoked ipsilateral excitation of the LSO in the mouse brain slice preparation (Wu and Kelly, '92). Binding studies using tritiated 6-cyano-7-nitroquinoxaline-2,3dione (CNQX) and CGS 19755, the latter an NMDA antagonist, indicate the presence of substantial populations of excitatory amino acid receptors in the LSO (Baker and Glendenning, '91). The possibility that glutamate may be the EAA-mediating ipsilateral excitation in the LSO is supported by the observation of heavy glutamate immunolabeling over $R$ terminals by this study, and the demonstration of enriched glutamate-like immunoreactivity over spherical cells in the cochlear nucleus (Ottersen and StormMathisen, '84; Madl et al., '86), the major source of $\mathrm{R}$ terminals, as suggested by Cant (' 84 ).

Uptake and immunocytochemical evidence suggest that GABA is present as a transmitter in the LSO. Incubations in tritiated GABA result in the labeling of a small population of synaptic terminals in the cat LSO (Schwartz, '85). Equally small numbers of GABA-immunoreactive puncta were observed scattered throughout the guinea pig LSO (Helfert et al., '89a) and similar patterns were observed in the rat LSO using antibodies raised against glutamic acid decarboxylase, the synthetic enzyme for GABA (Roberts and Ribak, '87). The results of the present study support our preliminary observations that GABA immunoreactivity over synaptic terminals in the guinea pig LSO is confined to the small number of $\mathrm{P}$ terminals (Helfert et al., ' $88 \mathrm{~b}$ ).
Ipsilateral excitation of LSO neurons may be driven by "glutamatergic" $R$ terminals originating from the ipsilateral cochlear nucleus. Both the LSO and MSO receive direct excitatory input by way of the spherical cells of the anteroventral cochlear nucleus (Warr, '82; Glendenning et al., '85; Cant and Casseday, '86; Finlayson and Caspary, '89; Sanes, '90; Cant, '91; Wu and Kelly, '91). Studies in the MSO have shown that this input contacts the dendrites of MSO neurons with synaptic terminals containing round vesicles and forming asymmetric synaptic contacts (Perkins, '73; Lindsay, '75; Kiss and Majorossy, '83; Schwartz '84). The $R$ terminals observed in this study possess a similar morphology, which relates well to the high probability that many arise from the ipsilateral spherical cell population (Cant, '84, '91). If this is so, then spherical cells may use glutamate or some other excitant amino acid as their neurotransmitter because of the high levels of glutamate immunolabeling associated with their $\mathrm{R}$ terminals.

Contralaterally induced inhibition of LSO neurons is driven by glycinergic $F$ terminals from the MNTB. The results of this study and others support the supposition that most of the $\mathrm{F}$ terminals originate from glycinergic MNTB neurons, and thus convey inhibitory input to the LSO representing the contralateral ear. It is known that electrical stimulation of axons from the MNTB evokes inhibitory postsynaptic potentials from ipsilateral LSO neurons (Sanes, '90). The vast majority of MNTB neurons, the presumptive source of these axons, exhibit intense glycine-like immunoreactivity and are thought to use glycine as an inhibitory neurotransmitter (Wenthold et al., '87; Aoki et al., '88; Helfert et al., '89a). 'That these neurons are a major source of glycinergic input to the LSO is supported by lesion studies in which ablation of the guinea pig MNTB with the excitotoxin kainic acid resulted in a profound decrease in the number of perisomatic glycineimmunoreactive puncta in the LSO (Bledsoe et al., ' 90 ). The MNTB is a major source of F terminals in the LSO, as suggested by Cant (' 84 ) and a preliminary study in which the injection of the anterograde tracer biocytin into the MNTB of guinea pigs results in the labeling of $F$ terminals contacting the somata and dendrites of LSO neurons (Helfert, Altschuler and Bledsoe, unpublished observations). That $\mathrm{F}$ terminals are glycinergic is implied by this study.

The distribution of $\mathrm{F}$ terminals in guinea pigs is similar to that observed in cats (Cant, '84). They are positioned to mediate effective control over all excitatory currents entering the soma. They contact the surfaces of somata and proximal dendrites in large numbers, while most of the $R$ terminals are distributed further distally on the dendritic trees; i.e., the majority of the contralaterally induced inhibitory input occurs proximal to the ipsilaterally induced excitatory input. The strong, hyperpolarizing chloride currents resulting from the interaction of the glycine released

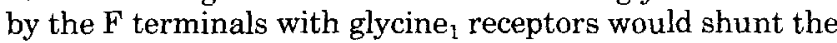
depolarization originating more distally. Such hyperpolarizing currents have been observed in several studies (Finlayson and Caspary, '89; Sanes, '90; Wu and Kelly, '91). The synaptic organization of the $F$ and $R$ terminals on LSO neurons would be consistent with their ability to respond to small changes in interaural intensity so that their firing rate is steadily reduced as the sound source moves along the azimuth away from the ipsilateral side (Boudreau and Tsuchitani, '70; Caird and Klinke, '83; Guinan et al., '72a, b; Sanes and Rubel, '88; Tsuchitani, '88; Caspary and Finlayson, '91). 
Possible functions of $\boldsymbol{P}$ terminals. Little is known about the $\mathrm{P}$ terminals located in the LSO, and nothing is known of the role GABA plays in LSO function. This study suggests that most of the $P$ terminals are located on dendrites, either individually or in pairs, where they can mediate control over the spread of excitation locally within dendritic trees. Thus, they may make modulatory adjustments in the excitatory responses of LSO units.

The sources of the perikarya that give rise to the $P$ terminals have yet to be identified, although potential ones can be discussed. In rats, gerbils, and guinea pigs, a large number of neurons exhibit GABA- or GAD-like immunoreactivity in the ventral nucleus of the trapezoid body (VNTB) (Thompson et al., '85; Moore and Moore, '87; Roberts and Ribak, '87; Helfert et al., '89a). This periolivary nucleus sends topographical projections bilaterally to the LSO in rats (Warr and Spangler, '89), as well as to other sites in the lower auditory brainstem, including the cochlear nucleus (of cats: Spangler et al., '87; and guinea pigs: Winter et al., '89; Ostapoff et al., '90; Shore et al., '91). Studies in rats show that the VNTB receives substantial tonotopic input from the inferior colliculus (Faye-Lund, '86; Saldaña, '90). Therefore, the VNTB may be an essential link in a descending pathway controlling neural activity in the LSO and cochlear nucleus. It is not known whether the projections from the VNTB to the LSO contact the principal neurons, whose axons ascend to terminate bilaterally in dorsal nucleus of the lateral lemniscus and inferior colliculus (Stotler, '53; Elverland, '78; Adams, '79; Brunso-Bechtold et al., ' 81 ; Glendenning and Masterton, ' 83 ; Nordeen et al., '83; Saint Marie et al., ' 89 ), lateral olivocochlear neurons. which project to the inner hair cells beneath the organ of Corti (Liberman et al., '80; Schwartz and Ryan, '86; Ryan et al., ' 87 ), or both. If the projection from the VNTB to the $\mathrm{LSO}$ is GABAergic, our results suggest that its GABA would be released by $P$ terminals.

A second supply of GABAergic input to LSO neurons may originate from intrinsic sources. In gerbils, guinea pigs, and rats, a large percentage of LSO neurons are immunoreactive for GABA or its synthetic enzyme glutamic acid decarboxylase (GAD) (Moore and Moore '87, Roberts and Ribak, '87; Helfert et al., '89a). In guinea pigs, the GABAimmunoreactive principal and marginal neurons coimmunolabel for glycine (Helfert et al., '89a). In the cat LSO, marginal neurons, and perhaps principal neurons, send intrinsic collaterals to neurons located nearby (Helfert and Schwartz, '86). If these collaterals arise from GABAergic neurons, then they may provide a source of ipsilateral inhibition and their terminals would be of the P type. Such inhibition has been demonstrated in the form of ipsilateral inhibitory sidebands recorded from LSO units in decerebrate cats (Brownell et al., '79). However, the cat LSO appears to possess a lower percentage of GABAergic neurons than that of rodents (Saint Marie et al., '89) and the functional significance of such a difference is presently unclear.

\section{Distribution of terminals on different cell types in the LSO}

In rodents as well as cats, the LSO is comprised of several cell types (Ollo and Schwartz, '79; Cant, '84; Helfert and Schwartz, '86, '87). For this reason it was not possible to determine the actual distribution of terminals on LSO neurons from the material generated for this study because most of the dendritic profiles observed in the electron micrographs were not connected to perikarya, thus they could not be assigned to specific cell types. Further studies using specific markers will be required to elucidate the distribution of the four terminal classes on individual cell types in the LSO. However, based on the patterns of axosomatic synaptic input, it is likely that the synaptic organization is similar among the different LSO cell types, with the exception of one, the lateral olivocochlear (OC) neuron.

In a study using gerbils, the synaptic organization of the inputs to tritiated D-aspartate-labeled lateral OC neurons was addressed (Helfert et al., '88a). A large percentage of the terminals contacting these neurons contained electronlucent, pleomorphic vesicles as well as granular vesicles. These terminals, which were sparsely distributed on the dendrites of lateral $\mathrm{OC}$ neurons, may correspond to SP terminals. If this is the case, then these terminals may be GABAergic and would play an important role in shaping the response characteristics of lateral $\mathrm{OC}$ neurons. Also contacting these neurons were a very small number of terminals that were similar morphologically to the F type. No other terminal types were observed, which would suggest that the lateral OC neurons do not receive excitatory input. Similar observations have been made in the cat (Spangler et al, ' 86 ) and rat (White, '86). However, the possibility should not be excluded that $\mathbf{R}$ terminals or other excitatory elements located distal to the inhibitory input escaped detection due to the inadequate labeling of the smallest caliber dendrites.

\section{Significance of cocontainment of amino acid transmitters}

The observation that GABA and glycine coexist within a subpopulation of synaptic terminals is not an isolated one. Numerous nonprimary endings coimmunolabel for GABA and glycine in the guinea pig cochlear nucleus (Altschuler et al., '89; Juiz et al., '89) as do type I Golgi endings in the rat cerebellum (Ottersen et al., '88; Hámori et al., '90). These terminals contain oval/pleomorphic vesicles and form axodendritic and axosomatic synapses with symmetric junctional specializations. Glycine receptor immunoreactivity has been observed postsynaptic to GABA and GADimmunolabeled presynaptic terminals in projection neurons of the guinea pig ventral cochlear nucleus (Oberdorfer et al., ' 87 ; Wenthold et al., ' 88 ) and in spinal motorneurons of rats (Triller et al., '87, '90). It is not known if the same synaptic arrangement occurs in the LSO, but since immunocytochemical and binding studies indicate that glycine receptors are abundant in this nucleus (Wenthold et al., ' 85 ; Sanes et al., '87; Glendenning and Baker, '88), the possibility exists.

The functional implications of the corelease of GABA and glycine from a single terminal presynaptic to glycine receptors are not well understood, but several hypotheses have been advanced. First, glycine may act on a postsynaptic target while GABA acts presynaptically to suppress transmitter release (Thompson and Gähwiler, ' 89 ). This hypothesis is supported by studies which indicate that presynaptic inhibition of transmitter release is mediated by $\mathrm{GABA}_{\mathrm{B}}$ receptors (Bowery, '89; Raiteri et al., '89; Baumann et al., '90; Chu et al., '90). Second, if GABA receptors are also postsynaptic to this terminal type, or at least located nearby on the postsynaptic membrane, then both glycine and GABA could act postsynaptically (for a review, see Triller et al., '90). Finally, GABA may interact allosterically with the 
glycine receptor, thereby modulating its binding characteristics as demonstrated in Mauthner cells (Werman, '80).

The demonstration of enhanced coimmunolabeling with glycine and glutamate over $F$ terminals is intriguing. As previously discussed, there is strong evidence that most, if not all, of the $\mathrm{F}$ terminals in the LSO are inhibitory and use glycine as their neurotransmitter. However, evidence for the coaction of excitatory and inhibitory amino acids has been published, so this possibility must be considered. Biochemical and pharmacological studies show that glycine modulates the NMDA excitatory amino acid receptor (Bonhaus et al., '87; Wong et al., '87; Fadda et al., '88; Minota et al., '89; Fletcher et al., '90; Monaghan, '90). In addition, $\mathrm{GABA}_{\mathrm{A}}$ responses are potentiated by glutamate and several of its analogues (Stelzer and Wong, ' 89 ).

Is there a mechanism by which glutamate modulates the glycine receptor? Evidence that this may be the case was revealed by a study using mouse brain slice preparations, in which the application of NMDA completely blocked contralaterally induced inhibition of LSO units without affecting excitatory responses in either the LSO or the MNTB (Wu and Kelly, '92). This finding, combined with the observation of substantial levels of NMDA receptor binding in the cat LSO (Baker and Glendenning, '91), suggests that an excitant amino acid such as glutamate may modulate contralaterally induced inhibition via NMDA receptors. The precise location of these receptors on LSO neurons or their presynaptic terminals has not been determined, so that one can only speculate on the mechanism of NMDAinduced disinhibition. Presynaptic inhibition of $\mathrm{F}$ terminals through axo-axonal synapses is unlikely because these endings have not been observed on $F$ terminals (Cant, ' 84 ; present study). However, it is possible that the NMDA receptors may be associated with the synapses formed by $\mathrm{F}$ terminals. Hence, modulatory disinhibition of LSO neurons may be mediated by the interaction of glutamate released by the $\mathrm{F}$ terminals with NMDA receptors located nearby, perhaps associated with the glycine receptors.

The elevated levels of glutamate immunolabeling in $\mathbf{F}$ terminals may also be explained by the high metabolic activity associated with contralaterally induced suppression of LSO activity. The LSO exhibits high 2-deoxyglucose (2-DG) activity in the presence of contralateral acoustic stimulation, which was attributed to the elevated metabolism associated with inhibitory synaptic activity (Nudo and Masterton, '86). However, it could not be determined if the site of 2-DG uptake was presynaptic, postsynaptic or both. Indeed, whether the elevated level of glutamate observed in $F$ terminals is related to metabolic activity, a neurotransmitter/neuromodulator pool, or both, remains to be seen. Further studies addressing the localization of glutamate receptors at the ultrastructural level should assist in answering this question.

\section{ACKNOWLEDGMENTS}

The authors thank Linda Gaffney, Sherri Williams, and Eric Wolf for their excellent technical assistance, Dr. Michael Myers for his advice and assistance in the statistical analyses, and Drs. Donald M. Caspary and Ilsa R. Schwartz for their comments on the manuscript. This research was supported by NIH grants NS-05785, NS-07106, NS-24369 and by grants from the Deafness Research Foundation. Preliminary reports of some of this material have appeared (Helfert et al., 89b, '90).

\section{LITERATURE CITED}

Adams, J.C. (1979) Ascending projections of the inferior colliculus. J. Comp. Neurol. 183:519-538.

Altschuler, R.A., J.M. Juiz, R.H. Helfert, J.M. Bonneau, and R.J. Wenthold (1989) Immunocytochemical evidence for the co-localization of GABA and glycine in synaptic terminals of the lower auditory brainstem. Absts. Soc. Neurosci. 15:227 (Abstract).

Aoki, E., R. Semba, H. Keino, K. Kato, and S. Kashiwamata (1988) Glycine-like immunoreactivity in the rat auditory pathway. Brain Res. 442:63-71.

Baker, B.N., and K.K. Glendenning (1991) Excitatory amino acid receptors in the auditory brainstem of the cat. Absts. Midwinter Mtg, Assoc. Res. Otolaryngol. 14:10 (Abstract).

Baumann, P.A., P. Wicki, C. Stierlin, and P.C. Waldmeier (1990) Investigations on $\mathrm{GABA}_{\mathrm{B}}$ receptor-mediated autoinhibition of GABA release. Naunyn-Sehmiedeberg's Arch. Pharmacol. 341:88-93.

Beitz, A.J. (1990) Relationship of glutamate and aspartate to the periaqueductal gray-raphe magnus projection: Analysis using immunocytochemistry and microdialysis. J. Histochem. Cytochem. 38:1755-1765.

Bledsoe, S.C., C.R. Snead, R.H. Helfert, V. Prasad, R.J. Wenthold, and R.A. Altschuler (1990) Immunocytochemical and lesion studies support the hypothesis that the projection from the medial nucleus of the trapezoid body to the lateral superior olive is glycinergic. Brain Res. 517:189-194.

Bonhaus, D.W., B.C. Burge, and J.O. McNamara (1987) Biochemical evidence that glycine allosterically regulates an NMDA receptor-coupled ion channel. Eur. J. Pharmacol. 142:489-490.

Boudreau, J.C., and C. Tsuchitani (1970) Cat superior olive S-segment cell discharge to tonal stimulation. In W.D. Neff (ed): Contributions to Sensory Physiology. New York: Academic Press, pp. 143-213.

Bowery, N.G. (1989) GABA $_{B}$ receptors and their significance in mammalian pharmacology. Trends Pharmacol. Sci. 10:401-407.

Brownell, W.E., P.B. Manis, and L.A. Ritz (1979) Ipsilateral inhibitory responses in the cat lateral superior olive S-segment. Brain Res. 177:189193

Brunso-Bechtold, J.K., G.C. Thompson, and R.B. Masterton (1981) HRP study of the organization of auditory afferents ascending to central nucleus of inferior colliculus in cat. J. Comp. Neurol. 197:705-722.

Caird, D., and Klinke, R. (1983) Processing of binaural stimuli by cat superior olivary complex neurons. Exp. Brain Res. 52:385-399.

Cant, N.B. (1984) The fine structure of the lateral superior olivary nucleus of the cat. J. Comp. Neurol. 227:63-77.

Cant, N.B. (1991) Projections to the lateral and medial superior olive from the spherical and globular bushy cells of the anteroventral cochlear nucleus. In R.A. Altschuler, R.P. Bobbin, D.W. Hoffman, and B.M. Clopton (eds): Neurobiology of Hearing: The Central Auditory System. New York: Raven Press, pp. 99-120.

Cant, N.B., and J.H. Casseday (1986) Projections from the anteroventral cochlear nucleus to the lateral and medial superior olivary nuclei. J. Comp. Neurol. 247:457-476.

Caspary, D.M., and C.L. Faingold (1989) Non- $N$-methyl-D-aspartate receptors may mediate ipsilateral excitation at lateral superior olivary synapses. Brain Res. 503:83-90.

Caspary, D.M., and P.G. Finlayson (1991) Superior olivary complex: Functional neuropharmacology of principal cell types. In R.A. Altschuler, R.P. Bobbin, D.W. Hoffman, and B.M. Clopton (eds): Neurobiology of Hearing: The Central Auditory System. New York: Raven Press, pp. 141-162.

Chu, D.C.M., R.L. Albin, A.B. Young, and J.B. Penny (1990) Distribution and kinetics of $\mathrm{GABA}_{\mathrm{B}}$ binding sites in the rat central nervous system: $\mathrm{A}$ quantitative autoradiographic study. Neuroscience 34:341-357.

Clements, J.R., K.R. Magnusson, and A.J. Beitz (1990) Ultrastructural description of glutamate-, aspartate-, taurine-, and glycine-like immunoreactive terminals from five rat brain regions. J. Electron Microsc. Tech. 15:49-66

De Biasi, S., and A. Rustioni (1990) Ultrastructural immunocytochemical localization of excitatory amino acids in the somatosensory system. J. Histochem. Cytochem. 38:1745-1754.

Elverland, H.H. (1978) Ascending and intrinsic projections of the superior olivary complex in the cat. Exp. Brain Res. 32:117-134.

Fadda, E., W. Danysz, J.T. Wroblewski, and E. Costa (1988) Glycine and $\mathrm{D}$-serine increases the affinity of $N$-methyl-D-aspartate sensitive glutamate binding sites in rat brain synaptic membranes. Neuropharmacology 27:1183-1185.

Faye-Lund, H. (1986) Projection from the inferior colliculus to the superior olivary complex in the albino rat. Anat. Embryol. 175:35-52. 
Finlayson, P.G., and D.M. Caspary (1989) Synaptic potentials of chinchilla lateral superior olivary neurons. Hearing Res. 38:221-228.

Fletcher, E.J., P.M. Beart, and D. Lodge (1990) Involvement of glycine in excitatory neurotransmission. In O.P. Ottersen and J. Storm-Mathisen (eds): Glycine Neurotransmission. New York: John Wiley \& Sons, pp. 193-217.

Friauf, E., and J. Ostwald (1988) Divergent projections of physiologically characterized rat ventral cochlear nucleus neurons as shown by intraaxonal injection of horseradish peroxidase. Exp. Brain Res. 73:263-284.

Glendenning, K.K., and B.N. Baker (1988) Neuroanatomical distribution of receptors for three potential inhibitory neurotransmitters in the brainstem auditory nuclei of the cat. J. Comp. Neurol. 275:288-308.

Glendenning, K.K., and R.B. Masterton (1983) Acoustic chiasm: Efferent projections of the lateral superior olive. J. Neurosci. 3:1521-1537.

Glendenning, K.K., K.A. Hutson, R.J. Nudo, and R.B. Masterton (1985) Acoustic chiasm. II. Anatomical basis of binaurality in lateral superior olive of cat. J. Comp. Neurol. 232:261-285.

Godfrey, D.A., J.A. Parli, J.D. Dunn, and C.D. Ross (1988) Neurotransmitter microchemistry of the cochlear nucleus and superior olivary complex. In J. Syka and R.B. Masterton (eds): Auditory Pathways. New York: Plenum Press, pp. 107-121.

Goldberg, J.M., and P.B. Brown (1968) Functional organization of the dog superior olivary complex: An anatomical and electrophysiological study. J. Neurophysiol. 31:639-656.

Gray, E.G. (1959) Axo-somatic and axo-dendritic synapses of the cerebral cortex: An electron microscopic study. J. Anat. (Lond) 93:420-433.

Guinan, J.J., S.S. Guinan, and B.E. Norris (1972a) Single auditory units in the superior olivary complex. I. Responses to sounds and classifications based on physiological properties. Int. J. Neurosci. 4: 101-120.

Guinan, J.J., S.S. Guinan, and B.E. Norris (1972b) Single auditory units in the superior olivary complex. II. Locations of unit categories and tonotopic organization. Int. J. Neurosci. 4:147-166.

Hámori, J., J. Takács, and P. Petrusz (1990) Immunogold electron microscopic demonstration of glutamate and GABA in normal and deafferented cerebellar cortex: Correlation between transmitter content and synaptic vesicle size. J. Histochem. Cytochem. 38:1767-1777.

Harrison, J.M., and R. Irving (1964) Nucleus of the trapezoid body: Dual afferent innervation. Science 143:473-474.

Harrison, J.M., and W.B. Warr (1962) The cochlear nucleus and ascending pathways of the medulla. J. Comp. Neurol. 119:341-380.

Helfert, R.H., and I.R. Schwartz (1986) Morphological evidence for the existence of multiple neuronal classes in the cat lateral superior olivary nucleus. J. Comp. Neurol. 244:533-549.

Helfert, R.H., and I.R. Schwartz (1987) Morphological features of five neuronal classes in the gerbil lateral superior olive. Am. J. Anat. 179:55-69.

Helfert, R.H., I.R. Schwartz, and A.F. Ryan (1988a) Ultrastructural characterization of gerbil olivocochlear neurons based on differential uptake of ${ }^{3} \mathrm{H}-\mathrm{D}$-aspartic acid and a wheatgerm agglutinin-horseradish peroxidase conjugate from the cochlea. J. Neurosci. 8:3111-3123.

Helfert, R.H., J.M. Bonneau, R.J. Wenthold, and R.A. Altschuler (1988b) Distribution of GABA and glycine immunoreactive synapses in the guinea pig superior olivary complex. Soc. Abst. Neurosci. 14:487 (abstract).

Helfert, R.H., J.M. Bonneau, R.J. Wenthold, and R.A. Altsehuler (1989a) GABA and glycine immunoreactivity in the guinea pig superior olivary complex. Brain Res. 501:269-286.

Helfert, R.H., J.M. Juiz, S.C. Bledsoe, Jr., J.M. Bonneau, R.J. Wenthold, and R.A. Altschuler (1989b) Two classes of glutamate immunoreactive synaptic terminals in the guinea pig superior olivary complex. Absts. Soc. Neurosci. 15:941 (abstract).

Helfert, R.H., J.M. Juiz, S.C. Bledsoe, Jr., R.J. Wenthold, and R.A. Altschuler (1990) Glutamate immunoreactivity in the guinea pig medial nucleus of the trapezoid body. Absts. Midwinter Mtg., Assoc. Res. Otolaryngol. 13:57-58 (abstract).

Jenkins, W.M., and R.B. Masterton (1982) Sound localization: Effects of unilateral lesions in the central auditory system. J. Neurophysiol. 47:987-1016

Juiz, J.M., J.M. Bonneau, R.H. Helfert, R.A. Altschuler, and R.J. Wenthold (1989) GABA and glycine immunoreactivities in the guinea pig cochlear nucleus: Ultrastructural co-labeling studies. Absts. Midwinter Mtg., Assoc. Res. Otolaryngol. 12:12 (abstract).

Karnovsky, M.J. (1967) The ultrastructural basis of capillary permeability studied with peroxidase as a tracer. J. Cell Biol. 35:213-236.
Kiss, A., and K. Majorossy (1983) Neuron morphology and synaptic architecture in the medial superior olivary nucleus. Exp. Brain Res. 52:315-327.

Liberman, M.C. (1980) Efferent synapses in the inner hair-cell area of the cat cochlea: An electron microscopic study of serial sections. Hearing Res. 3:189-204.

Lindsay, B.G. (1975) Fine structure and distribution of axon terminals from the cochlear nucleus on neurons in the medial superior olivary nucleus of the cat. J. Comp. Neurol. 160:81-105.

Madl., J.E., A.A. Larson, and A.J. Beitz (1986) Monoclonal antibody specific for carbodiimide-fixed glutamate: Immunocytochemical localization in the rat. J. Histochem. Cytochem. 34:317-326.

Maley, B.E. (1990) Ultrastructural identification of neuropeptides in the central nervous system. J. Electron Microsc. Tech. 15:67-80.

Maley, B.E., M.G. Engle, S. Humphreys, D.A. Vascik, K.A. Howes, B.W Newton, and R.P. Elde (1990) Monoamine synaptic structure and localization in the central nervous system. J. Electron. Microsc. Tech. $15: 20-33$.

Masterton, R. B , K K. Glendenning and K.A. Hutson (1979) Preservation of trapezoid body fibers after biochemical ablation of superior olives with kainic acid. Brain Res. 173:156-159.

Maxwell, D.J., W.M. Christie, A.D. Short, J. Storm-Mathisen, and O.P. Ottersen (1990) Central boutons of glomeruli in the spinal cord of the cat are enriched with L-glutamate-like immunoreactivity. Neuroscience 36:93- 104 .

Minota, S., T. Miyazaki, M.Y. Wang, H.L. Read, and N.J. Dun (1989) Glycine potentiates NMDA responses in rat hippocampal CA1 neurons. Neurosci. Lett. 100:237-242.

Monaghan, D.T. (1990) Glycine modulation of NMDA receptors: Autoradiographic studies. In O.P. Ottersen and J. Storm-Mathisen (eds): Glycine Neurotransmission. New York: John Wiley \& Sons, pp. 219-237.

Montero, V.M., and R.J. Wenthold (1989) Quantitative immunogold analysis reveals high glutamate levels in retinal and cortical synaptic terminals in the lateral geniculate nucleus of the macaque. Neuroscience 31:639-647.

Moore, J.K., and R.Y. Moore (1987) Glutamic acid decarboxylase-like immunoreactivity in brainstem auditory nuclei of the rat. J. Comp. Neurol. 260:157-174.

Moore, M.J., and D.M. Caspary (1983) Strychnine blocks binaural inhibition in lateral superior olivary neurons. J. Neurosci. 3:237-242.

Morest, D.K., and M. Jean-Baptiste (1975) Degeneration and phagocytosis of synaptic endings and axons in the medial trapezoid nucleus of the cat. J. Comp. Neurol. 162:135-155.

Nordeen, K.W., J.P. Killackey, and L.M. Kitzes (1983) Ascending auditory projections to the inferior colliculus in the adult gerbil, Meriones unguiculatus. J. Comp. Neurol. 214:131-143.

Nudo, R.J., and R.B. Masterton (1986) Stimulation-induced ${ }^{\left[{ }^{14} \mathrm{C} / 2-\right.}$ deoxyglucose labeling of synaptic activity in the central auditory system. J. Comp. Neurol. 245:553-565.

Oberdorfer, M.D., M.H. Parakkal, R.A. Altschuler, and R.J. Wenthold (1987) Co-localization of glycine and GABA in the cochlear nucleus. Absts. Soc. Neurosci. 13:544 (abstract).

Ollo, C., and I.R. Schwartz (1979) The superior olivary complex in C57B16 mice. Am. J. Anat. 155:349-374.

Ostapoff, E.-M., D.K. Morest, and S.J Potashner (1990) Uptake and retrograde transport of $\left.\mid{ }^{3} \mathrm{H}\right] \mathrm{GABA}$ from the cochlear nucleus to the superior olivary complex in the guinea pig. J. Chem. Neuroanat. 3:285-295.

Ottersen, O.P., and J. Storm-Mathisen (1984) Neurons containing or accumulating transmitter amino acids. In Handbook of Chemical Neuroanatomy. Vol. 3. Classical Transmitters and Transmittor receptors in the CNS, Part II. Amsterdam: Elsevier, pp. 141-246.

Ottersen, O.P., J. Storm-Mathisen, and P. Somogyi (1988) Co-localization of glycine-like and GABA-like immunoreactivities in Golgi terminals in the rat cerebellum: A postembedding light and electron microscopic study. Brain Res. 45:342--353.

Perkins, R.E. (1973) An electron microscopic study of synaptic organization in the medial superior olive of normal and experimental chinchillas. J. Comp. Neurol. 148:387-416.

Peyret, D., G. Campistron, M. Geffard, and J.-M. Aran (1987) Glycine immunoreactivity in the brainstem auditory and vestibular nuclei of the guinea pig. Acta Otolaryngol. 104:71-76

Raiteri, M., G. Bonnano, and E. Fedele (1989) Release of $\mathrm{g}-[3 \mathrm{H}]$ aminobutyric acid (GABA) from electrically stimulated rat cortical slices and its modulation by GABA $_{B}$ autoreceptors. J. Pharm. Exp. Ther. 250:648653. 
Rasmussen, G.L. (1946) The olivary peduncle and other fiber connections of the superior olivary complex. J. Comp. Neurol. 84:141-219.

Ribak, C.E., and R.C. Roberts (1990) GABAergic synapses in the brain identified with antisera to GABA and its synthesizing enzyme, glutamate decarboxylase. J. Electron Microsc. Tech. 15:34-48.

Roberts, R.C., and C.E. Ribak (1987) GABAergic neurons and axon terminals in the brainstem auditory nuclei of the gerbil. J. Comp. Neurol. 258:267-280.

Ryan, A.F., I.R. Schwartz, R.H. Helfert, E. Keithley, and Z.-X. Wang (1987) Selective retrograde labeling of lateral olivocochlear neurons in brainstem based on preferential uptake of ${ }^{3} \mathrm{H}$-D-aspartic acid in the cochlea. $\mathrm{J}$. Comp. Neurol. 255:606-616.

Saint Marie, R.L., E.-M. Ostapoff, D.K. Morest, and R.J. Wenthold (1989) Glycine immunoreactive projection of the cat lateral superior olive: Possible role in midbrain ear dominance. J. Comp. Neurol. 279:382-396.

Saldaña, E. (1990) The rat colliculo-olivary projection is tonotopic. Absts. Soc. Neurosci. 16:716 (abstract)

Sanes, D.H. (1990) An in vitro analysis of sound localization mechanisms in the gerbil lateral superior olive. J. Neurosci. 10:3494-3506.

Sanes, D.H., and E.W. Rubel (1988) The ontogeny of inhibition and excitation in the gerbil lateral superior olive. J. Neurosci. 8:682-700.

Sanes, D.H., W.H. Geary, G.F. Wooten, and E.W. Rubel (1987) Quantitative distribution of the glycine receptor in the auditory brain stem of the gerbil. J. Neurosci. 7:3793-3802.

Schwartz, I.R. (1984) Axonal organization in the cat medial superior olive. Cont. Sensory Physiol. 8:99-129.

Schwartz, I.R. (1985) Autoradiographic studies of amino acid labelling of neural elements in the auditory brain stem. In D.G. Drescher (ed): Auditory Biochemistry. Springfield: Thomas, pp. 258-277.

Schwartz, I.R., and A.F. Ryan (1986) Amino acid labeling patterns in the efferent innervation of the cochlea: An electron microscopic autoradiographic study. J. Comp. Neurol. 246:500-512.

Shore, S.E., R.H. Helfert, S.C. Bledsoe, Jr., R.A. Altschuler, and D.A Godfrey (1991) Descending projections to the dorsal and ventral divisions of the cochlear nucleus in guinea pig. Hearing Res. 52:255-268.

Somogyi, P., K. Halasy, J. Somogyi, J. Storm-Mathisen, and O.P. Ottersen (1986) Quantification of immunogold labelling reveals enrichment of glutamate in mossy and parallel fiber terminals in cat cerebellum. Neuroscience 19:1045-1050.

Spangler, K.M., W.B. Warr, and C.K. Henkel (1985) The projections of principal cells of the medial nucleus of the trapezoid body in the cat. J. Comp. Neurol. 238:249-262.

Spangler, K.M., J.S. White, and W.B. Warr (1986) Electron microscopic features of axon terminals on olivocochlear neurons in the cat. Absts. Midwinter Mtg., Assoc. Res. Otolaryngol. 9:37-38 (abstract).

Spangler, K.M., N.B. Cant, C.K. Henkel, G.R. Farley, and W.B. Warr (1987) Descending projections from the superior olivary complex to the cochlear nucleus of the cat. J. Comp. Neurol. 259:452-465.

Spirou, G., W.E. Brownell, and M. Zidanic (1990) Recordings from cat trapezoid body and HRP labeling of globular bushy cell axons. J. Neurophysiol. 63:1169-1190.

Stelzer, A., and R.K.S. Wong (1989) GABA A $_{\mathrm{A}}$ responses in hippocampal neurons are potentiated by glutamate. Nature 337:170-173.

Stotler, W.A. (1953) An experimental study of the cells and connections of the superior olivary complex of the cat. J. Comp. Neurol. 98:401-432.

Thompson, G.C., A.M. Cortez, and D.M.-K. Lam (1985) Localization of GABA immunoreactivity in the auditory brainstem of guinea pigs. Brain Res. 339:119-122.

Thompson, S.M., and B.H. Gähwiler (1989) Activity-dependent disinhibition. III. Desensitization and $\mathrm{GABA}_{\mathrm{B}}$ receptor-mediated presynaptic inhibition in the hippocampus in vitro. J. Neurophysiol. 61:524-533.

Tolbert, L.P., D.K. Morest, and D.K. Yurgelun-Todd (1982) The neuronal architecture of the anteroventral cochlear nucleus of the cat in the region of the cochlear nerve root: Horseradish peroxidase labelling of identified cell types. Neuroscience 7:3031-3052.

Triller, A., F. Cluzeaud, and H. Korn (1987) Gamma-aminobutyric acidcontaining terminals can be apposed to glycine receptors at central synapses. J. Cell Biol. 104:947- 956.

Triller, A., F. Cluzeaud, and T. Seitanidou (1990) Immunocytochemica localization of the glycine receptor. In O.P. Ottersen and J. Storm Mathisen (eds): Glycine Neurotransmission. Chichester: John Wiley \& Sons, pp. 83-110.

Tsuchitani, C. (1977) Functional organization of lateral cell groups of the cat superior olivary complex. J. Neurophysiol. 40:296-318.

Tsuchitani, C. (1988) The inhibition of cat superior olive unit excitatory responses to binaural tone bursts. II. The sustained discharges. J Neurophysiol. 59: 184-211

Tsuchitani, C., and J.C. Boudreau (1966) Single unit analysis of cat superior olive S-segment with tonal stimuli. J. Neurophysiol. 29:684-697.

Warr, W.B. (1966) Fiber degeneration following lesions in the anterior ventral cochlear nucleus of the cat. Exp. Neurol. 14:453-474

Warr, W.B. (1972) Fiber degeneration following lesions in the multipolar and globular cell areas in the ventral cochlear nucleus of the cat. Brain Res. 40:247-270.

Warr, W.B. (1982) Parallel ascending pathways from the cochlear nucleus neuroanatomical evidence of functional specialization. Contrib. Sensory Physiol. 7:1-38.

Warr, W.B., and K.M. Spangler (1989) A novel projection of the ventral nucleus of the trapezoid body in the rat. Absts. Soc. Neurosci. 15:745 (abstract)

Wenthold, R.J., D. Huie, R.A. Altschuler, and K.A. Reeks (1987) Glycine immunoreactivity localized in the cochlear nucleus and superior olivary complex. Neuroscience 2:897-912.

Wenthold, R.J., M.H. Parakkal, M.D. Oberdorfer, and R.A. Altsculer (1988) Glycine receptor immunoreactivity in the ventral cochlear nucleus of the guinea pig. J. Comp. Neurol. 276:423-435.

Wenthold, R.J., H. Betz, K.A. Reeks, M.H. Parakkal, and R.A. Altschuler (1985) Localization of glycinergic synapses in the cochlear nucleus and superior olivary complex with monoclonal antibodies specific for the glycine receptor. Absts. Soc. Neurosei. 11:1048 (abstract).

Wenthold, R.J., J.M. Zemple, M.H. Parakkal, K.A. Reeks, and R.A. Altschuler (1986) Immunocytochemical localization of GABA in the cochlear nucleus of the guinea pig. Brain Res. 380:7-18.

Werman, R. (1980) GABA modulates the glycine-receptor interaction in Mauthner cell allosterically. In U.Z. Littauer, Y. Dudai, I. Silman, V.I Teichberg, and Z. Vogel (eds): Transmitters and Their Receptors. Chichester: John Wiley \& Sons, pp. 393-404.

White, J.S. (1986) Differences in the ultrastructure of labyrinthine efferent neurons in the albino rat. Absts. Midwinter Mtg., Assoc. Res. Otolaryngol. 9:34-35 (abstract).

Winter, I.M., D. Robertson, and K.S. Cole (1989) Descending projections from auditory brainstem nuclei to the cochlea and cochlear nucleus of the guinea pig. J. Comp. Neurol. 280:143-157.

Wong, E.H.F., A.R. Knight, and R. Ransom (1987) Glycine modulates [ ${ }^{3} \mathrm{H}$ ] MK 801 binding to the NMDA receptor in rat brain. Eur. J. Pharmacol. 142:487-488.

Wu, S.H., and J.B. Kelly (1991) Physiological properties of neurons in the mouse superior olive: Membrane characteristics and postsynaptic responses studied in vitro. J. Neurophysiol. 65:230-246.

Wu, S.H., and J.B. Kelly (1992) NMDA, non-NMDA and glycine receptors modulate binaural interaction in the lateral superior olive: Physiological evidence from mouse brain slice. Neurosei. Lett. 134:257-260.

Zook, J.M., and R.M. DiCaprio (1988) Intracellular labeling of afferents to the lateral superior olive in the bat, Eptesicus fuscus. Hearing Res. $34: 141-148$ 